\title{
TBP, a universal eukaryotic transcription factor?
}

\author{
Nouria Hernandez \\ Cold Spring Harbor Laboratory, Cold Spring Harbor, New York 11742
}

In eukaryotes, transcription is carried out by three different RNA polymerases, RNA polymerases I, II, and III, each of which is dedicated to the transcription of different sets of genes. The genes in each class contain characteristic promoters, which often consist of two types of elements: the basal promoter elements and the modulator promoter elements. The basal promoter elements are sufficient to determine RNA polymerase specificity and direct low levels of transcription, whereas the modulator elements enhance or reduce the basal levels of transcription. None of the RNA polymerases can recognize its target promoters directly. Instead, basal promoter elements are first recognized by specific transcription factors, which then recruit the correct RNA polymerase. Because the RNA polymerase I, II, and III promoters contain distinctive elements, it had long been assumed that they achieve recruitment of the correct RNA polymerase by binding very different transcription factors.

Consistent with this view, the transcription factors required for RNA polymerase I, II, and III transcription can be separated from each other chromatographically, as shown in Figure 1. This scheme separates a cellular extract into four fractions, termed A, B, C, and D (Matsui et al. 1980; Segall et al. 1980; Samuels et al. 1982). RNA polymerase II transcription requires the $\mathrm{A}, \mathrm{C}$, and $\mathrm{D}$ fractions; the $\mathrm{A}$ and $\mathrm{C}$ fractions are now known to contain several factors. The D fraction contains TFIID, a factor that binds to the TATA box present in a large number of RNA polymerase II promoters (for reviews, see Sawadogo and Sentenac 1990; Buratowski and Sharp 1992; Zawel and Reinberg 1993).

TFIID proved very difficult to purify and was not characterized in detail until 1988, when an activity capable of functionally replacing mammalian TFIID in a reconstituted in vitro transcription system was identified in Saccharomyces cerevisiae extracts (Buratowski et al. 1988; Cavallini et al. 1988). This was a major breakthrough because, unlike mammalian TFIID, the yeast activity could be purified to homogeneity and turned out to correspond to a single polypetide of $27 \mathrm{kD}$ (Cavallini et al. 1989; Hahn et al. 1989; Horikoshi et al. 1989a; Schmidt et al. 1989). The cDNA encoding the yeast TATA box-binding protein (TBP) was then cloned by several groups (Cavallini et al. 1989; Hahn et al. 1989; Horikoshi et al. 1989b; Schmidt et al. 1989|, and the protein sequence information was used to isolate TBP-encoding
cDNAs from several other species, including Drosophila (Hoey et al. 1990; Muhich et al. 1990) and humans (Hoffman et al. 1990b; Kao et al. 1990; Peterson et al. 1990). Like the yeast protein, the Drosophila and human TBPs are small proteins of $38 \mathrm{kD}$, a surprising result because the molecular mass of the mammalian TATA box-binding factor TFIID was known to be $\sim 750 \mathrm{kD}$ (Nakajima et al. 1988; Conaway et al. 1990, 1991). In addition, like TFIID, these TBPs could mediate basal RNA polymerase II transcription, but unlike TFIID, they could not respond to transcriptional activators (Hoey et al. 1990; Hoffman et al. 1990b; Peterson et al. 1990; Pugh and Tjian 1990; Smale et al. 1990). This observation led to the hypothesis that transcriptional activation requires activities besides TBP present in the TFIID fraction, which were termed coactivators (Peterson et al. 1990; Pugh and Tjian 1990). Biochemical analyses then revealed that TFIID is a large complex consisting of TBP and a number of TBP-associated factors or TAFs (Dynlacht et al. 1991; Tanese et al. 1991). The TFIID complex could mediate transcriptional activation, indicating that the coactivator function is provided by the TAFs (Dynlacht et al. 1991; Tanese et al. 1991; Zhou et al. 1992, 1993; Hoey et al. 19931.

The identification of TBP as the TATA box-binding subunit of TFIID suggested that TBP is exclusively involved in transcription of TATA-containing RNA polymerase II promoters. However, even though RNA polymerase I, II, and III promoters are generally very different in structure, there are exceptions. Among the most striking are the promoters of the human small nuclear RNA (snRNA) genes, which encode small RNA molecules involved in the processing of other RNA molecules. Most of these genes are transcribed by RNA polymerase II; however, the U6 snRNA gene is transcribed by RNA polymerase III. All of the snRNA promoters are very similar in structure, except for the presence of a TATA box in the RNA polymerase III U6 promoter (Fig. 2). Paradoxically, the TATA box in the U6 promoter is responsible for selecting RNA polymerase III over RNA polymerase II (Mattaj et al. 1988; Lobo and Hernandez 1989); and even more paradoxically, transcription from the U6 promoter requires TBP (Lobo et al. 1991; Margottin et al. 1991; Simmen et al. 1991). This discovery was the first indication that TBP is not just an RNA polymerase II transcription factor and led to the suggestion that TBP 
Figure 1. Elution profile of RNA polymerase I, II, and III transcription factors on a phosphocellulose (P11) column. The boxed factors contain TBP, which can be detected by immunoblot in the $\mathrm{B}, \mathrm{C}$, and $\mathrm{D}$ fractions.

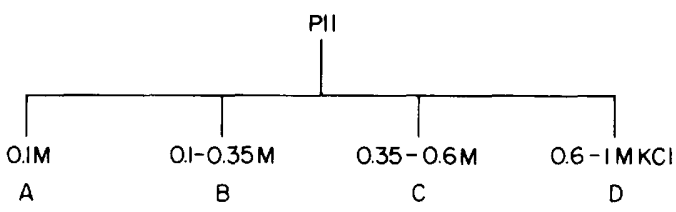

PolI

transcription foctors

PolI

Iranscription foctors

IIA,IJ

PolD

IB, IE, IF, IH

PolIII

transcription foctors

IIIA

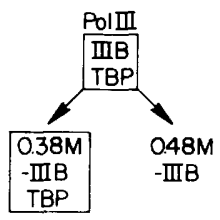

Pol III

IIIC

PolI and III

transcription factor (snRNA promoters) might be involved in transcription by all three RNA polymerases (Lobo et al. 1991). That this is the case has been shown both biochemically and genetically. TBP is involved in RNA polymerase I transcription as a subunit of the SL1 transcription factor (Comai et al. 1992) and in transcription from TATA-less RNA polymerase III promoters (R. White et al. 1992) as a subunit of TFIIIB (Huet and Sentenac 1992; Kassavetis et al. 1992; Lobo et al. 1992; Simmen et al. 1992; Taggart et al. 1992; White and Jackson 1992) (see Fig. 1). The universal role of TBP was also demonstrated in yeast, where mutations in TBP affect transcription by all three RNA polymerases (Cormack and Struhl 1992; Schultz et al. 1992). Thus, TBP is part of the initiation complexes formed on TATA-containing and TATA-less RNA polymerase I, II, and III promoters.

With the characterization of TFIID, SL1, and TFIIIB as TBP-containing complexes (Fig. 1), we are very close to reproducing transcription with entirely characterized factors. For example, except for TFIIJ, all of the basal transcription factors involved in RNA polymerase II transcription of TATA-containing mRNA-type promot- ers have now been purified to homogeneity; and in several cases, corresponding cDNAs have been isolated (for review, see Zawel and Reinberg 1992). Such accomplishments have led to dramatic advances in our understanding of how the RNA polymerase I, II, and III initiation complexes are assembled. The emerging picture is one in which a common step, the incorporation of TBP, is achieved through different but related pathways, leading to the recruitment of a specific RNA polymerase.

In this review I describe our current understanding of the role played by TBP during assembly of RNA polymerase I, II, and III initiation complexes and during activation of RNA polymerase II transcription.

\section{Structure of TBP}

TBP-encoding cDNAs have been cloned from a number of organisms. In most cases, TBP is encoded in a single gene, but some organisms, including Arabidopsis, have two TBP genes that encode highly similar proteins (Gasch et al. 1990). In addition, a Drosophila gene product encoding a protein with considerable similarity to

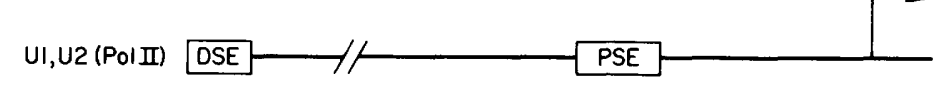

Figure 2. Structure of the RNA polymerase II (U1 and U2) and III (U6) snRNA promoters. The distal sequence element (DSE), proximal sequence element (PSE), and TATA box are indicated. The arrow marks the transcriptional start site.

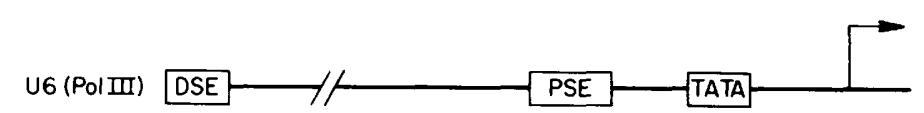


TBP has been characterized (Crowley et al. 1993). However, this protein, termed TRF, is expressed in a highly restricted manner in the embryo and cannot replace TBP for basal transcription in vitro, suggesting that it does not correspond to a basal transcription factor /Crowley et al. 1993). As shown in Figure 3A, comparison of the deduced TBP amino acid sequences reveals the presence of a nonconserved amino-terminal domain and a highly conserved carboxy-terminal domain, which invariably contains two copies of a long imperfect repeat of 61-62 amino acids (indicated by arrows), as well as short basic repeats (marked + ). The carboxy-terminal core domains of all characterized TBPs are $\geqslant 75 \%$ identical to that of human TBP, with the exception of that of Plasmodium falciparum TBP, which is only $38 \%$ identical to the human TBP core domain. The entire core domain constitutes a remarkably large DNA-binding domain that interacts with DNA as a monomer (Horikoshi et al. 1990). TBP contacts DNA through interactions with the minor groove (Starr and Hawley 1991; D. Lee et al. 1991) and induces a bend around the TATA element (Horikoshi et al. 1992).

The structure of one of the Arabidopsis thaliana TBPs, TBP-2, has been determined by X-ray crystallography at $2.6 \AA$ resolution and is shown in Figure 3B (Nikolov et al. 1992). The entire core domain folds into an elegant sym-
A

Mouse

Drosophilo

Arabidopsis-1

Arabidopsis-2

Maize-1

Potato

Wheat-1

Wheat-2

Schizosoccharomyces pombe

Saccharomyces cerevisiae

Dictyostelium discoideum

Plasmodium falciparum
Maize-2

Acanthamoeba castellanii

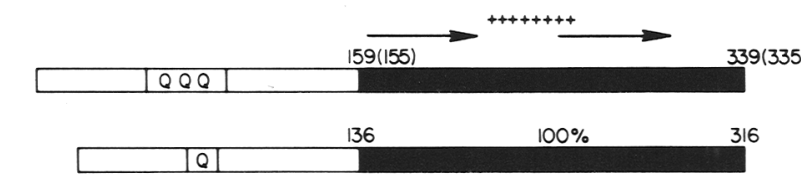

$173 \quad 88 \%$

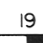

19
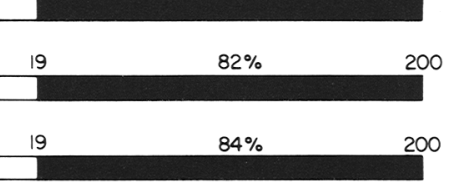

19
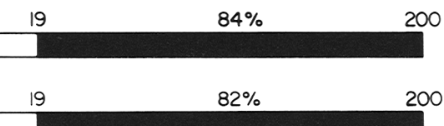

52
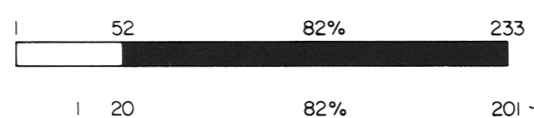

$82 \%$

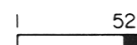

$80 \%$

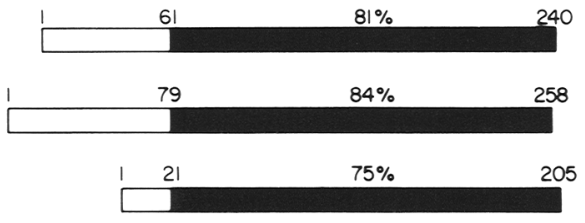

B

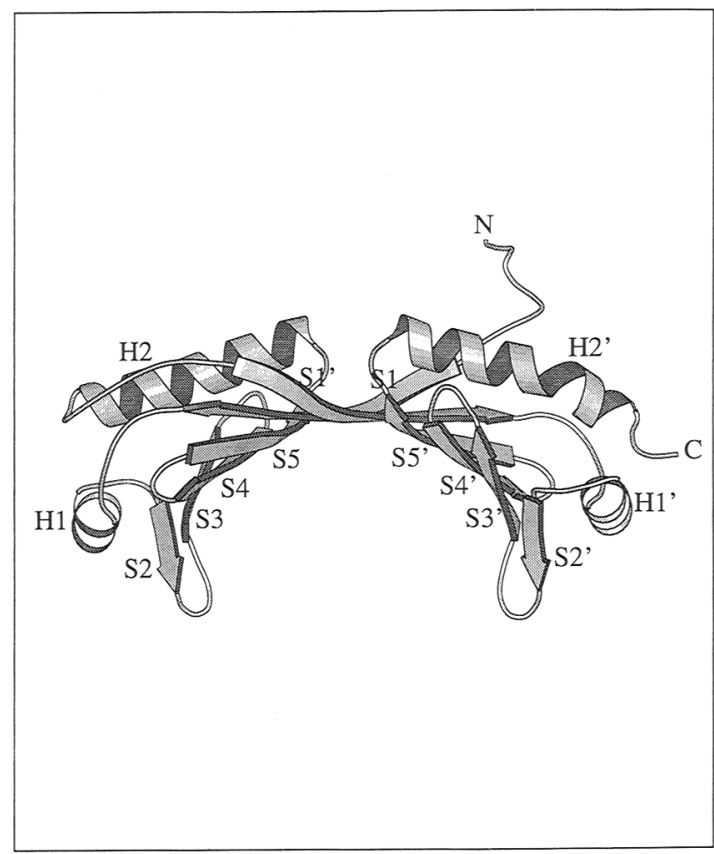

Figure 3. (A) Schematic representation of TBPs from different species. The conserved carboxy-terminal domain is the solid region. The direct repeats and the basic repeats are indicated. In the human and Drosophila proteins, glutamine stretches are marked (boxes labeled Q). References: Human (Hoffmann et al. 1990 b; Kao et al. 1990; Peterson et al. 1990); mouse (Tamura et al. 1991); Drosophila (Hoey et al. 1990; Muhich et al. 1990); A. thaliana (Gasch et al. 1990); maize (Haass and Feix 1992); potato (Holdsworth et al.

1992); wheat-1 (Kawata et al. 1992); wheat-2 (Apsit et al. 1993); Schizosaccharomyces pombe (Fikes et al. 1990; Hoffmann et al. 1990a); S. cerevisiae (Cavallini et al. 1989; Hahn et al. 1989; Horikoshi et al. 1989b; Schmidt et al. 1989); Acanthamoeba castellanii (Wong et al. 1992); Dictyostelium discoideum (J.E. Blume, D.R. Shaw, and H.L. Ennis; GenBank accession number M64861); and P. falciparum (McAndrew et al. 1993). Note that the human TBP described by Hoffman et al. (1990b) contains four less glutamines in the glutamine stretch than the human TBPs described by Kao et al. (1990) and Peterson et al. (1990). (B) Structure of Arabidopsis TBP-2, reprinted, with permission, from Nikolov et al. (1992). The sequence extends from $\beta$-strand 1 (S1) (amino acids 21-33) through $\alpha$-helix 1 (H1) (amino acids 40-46), S2 (amino acids 50-52), S3 (amino acids 59-63), S4 (amino acids 70-74), S5 (amino acids 78-84), H2 (amino acids 87-103), S1' (amino acids 111-123), H1' (amino acids 130-136), S2' (amino acids 141-143), S3' (amino acids 150-154), S4' (amino acids 161-165), S5' (amino acids 169-175), to H2 (amino acids 178-194). The direct repeats extend from the fifth amino acid of S1 (and S1') (amino acids 25 and 115) to the one following S5 (and S5') (amino acids 85 and 176). The basic repeats map to H2, the connection between $\mathrm{H} 2$ and $\mathrm{S}^{\prime}$, and the very beginning of $\mathrm{S}^{\prime}$. The locations of mutations that affect TBP interactions with DNA or other proteins are indicated in Table 1. 
metrical structure that resembles a saddle. The symmetry extends beyond the direct sequence repeats, such that although the two halves are similar in structure, they differ in sequence. This structure is likely to be conserved in all known TBPs, because it is compatible with the amino acid changes that distinguish core domains from different species. The concave underside and convex topside of the saddle are lined by $\beta$-sheets and $\alpha$-helices, respectively. The half cylindrical space formed by the underside of the molecule is wide enough to accommodate DNA, and as detailed in Table 1, all of the characterized mutations that affect the efficiency or the specificity of TBP-DNA interactions map to the underside or edges of the saddle. This suggests that this side lies on the DNA and that the $\alpha$-helices on the convex side are accessible for interactions with other factors. Table 1 shows that mutations affecting protein-protein interactions map to the convex side. Even though the saddle structure of TBP results in an extended surface available for protein-protein interactions, it remains puzzling how such a small protein can accommodate the large number of protein-protein interactions that occur during transcription initiation.

\section{TBP and transcription by RNA polymerase I}

TBP is recruited to RNA polymerase I, II, and III basal promoter elements through different strategies, which involve either direct binding to the DNA in the case of TATA-containing promoters, or protein-protein interactions in the case of TATA-less promoters. The RNA polymerase I promoters, which direct transcription of the large rRNA genes, do not contain a TATA box (for review, see Reeder 1992). As shown in Figure 4A, the human rRNA promoters are instead composed of a core element that overlaps the transcriptional start site and an upstream control element (UCE) located upstream of position -100 that stimulates transcription 10 - to 100 fold. Transcription requires two factors in addition to RNA polymerase I: the upstream binding factor (UBF) and the selectivity factor 1 (SL1), which contains TBP (for review, see Reeder 1992). UBF has been purified, and corresponding cDNAs have been cloned from human and Xenopus cells. It binds in a sequence-specific manner to both the core and the UCE, but for simplicity it is shown binding only to the core in Figure 4A. In contrast, SL1, which has been characterized in rodent and human cells (Learned et al. 1985; Bell et al. 1990), has no (human SL1) or very little (mouse SL1) affinity for the rRNA promoter but binds cooperatively with UBF (Learned et al. 1986; Bell et al. 1988, 1990; Jantzen et al. 1992). These observations suggest that RNA polymerase I initiation complexes are assembled as illustrated in Figure 4. UBF binds to the DNA first (Fig. 4A), and this allows the recruitment of SL1 (Fig. 4B), which greatly stabilizes the initiation complex and, subsequently, RNA polymerase I (Fig. 4C).

Human SL1 consists of TBP in tight association with three other TAFs, of 48, 63, and $110 \mathrm{kD}$ /Comai et al. 1992). The TAFs are essential for transcription, because
SL1 cannot be replaced by recombinant TBP. This is in stark contrast to transcription from TATA-containing RNA polymerase II promoters, where recombinant TBP on its own is sufficient to direct basal levels of transcription (see below), and suggests that the SLl TAFs are involved in recruiting TBP to the RNA polymerase I promoter through protein-protein interactions with UBF and interactions with the DNA. Perhaps protein-protein interactions with UBF induce a conformational change in SL1 that unmasks a DNA-binding domain, either in TBP or in one of the TAFs.

\section{Role of TFIID and TBP in transcription by RNA polymerase II}

RNA polymerase II promoters can be divided into two large classes: the mRNA promoters and the snRNA promoters. The mRNA promoters can in turn be divided into two classes depending on whether or not they contain a TATA box. The basal TATA box-containing mRNA promoters may consist of either the TATA box alone or the TATA box and an initiator sequence (Inr) that spans the transcriptional start site. The basal TATA-less mRNA promoters consist of just the Inr. Both the TATA box and the Inr appear to recruit the TBP-containing complex TFIID. TBP on its own can, however, replace the TFIID complex to direct basal levels of transcription from TATA-containing promoters in vitro, suggesting that direct interactions exist between TBP and components of the basal transcription machinery.

The basal RNA polymerase II snRNA promoters consist of a proximal sequence element (PSE), which is also present in RNA polymerase III snRNA promoters (see Fig. 2). Transcription from these promoters has been shown recently to require $\mathrm{TBP}$, which is recruited by the PSE.

\section{Basal transcription from TATA-containing RNA polymerase II $m$ RNA promoters}

Figure 5, A-D, shows the assembly of an initiation complex on an RNA polymerase II TATA-containing mRNA promoter (Buratowski et al. 1989; Maldonado et al. 1990; Meisterernst and Roeder 1991). The first step is the binding of TBP (or TFIID) to the TATA box (Fig. 5A). This reaction can be facilitated by TFIIA, which interacts with TBP through three lysine residues located in the basic repeat region on the convex surface of TBPs (Fig. 3B; Table 1) (Buratowski and Zhou 1992a; Lee et al. 1992). The role of TFIIA is not entirely understood, however. It is required for transcription in systems reconstituted with the TFIID complex but not in all systems reconstituted with TBP (Maldonado et al. 1990; Sumimoto et al. 1990; Meisterernst et al. 1991; Cortes et al. 1992) and is thought to function by dissociating a repressor associated with TBP in the TFIID complex (Cortes et al. 1992). After TBP is bound to the TATA box, TFIIB (Fig. 5B), followed by RNA polymerase II, which is associated with TFIIF (Fig. 5C), join the initiation complex. 
TBP can interact with the carboxy-terminal domain of TFIIB, and this interaction is abolished by deletion of amino acids 202-221 in TBP (Ha et al. 1993; see Table 1). In addition, TFIIB contacts TFIIF (Ha et al. 1993), and both TBP and TFIIB contact RNA polymerase II (Usheva et al. 1992; Ha et al. 1993). After the binding of RNA polymerase II and TFIIF, the RNA polymerase II transcription factors IIE, IIH, and IIJ join the initiation complex (Fig. 5D), and transcription can proceed upon addition of ribonucleotide triphosphates (for reviews, see Sawadogo and Sentenac 1990; Roeder 1991; Zawel and Reinberg 1992, 1993).

The carboxyl terminus of RNA polymerase II consists of a repeated heptad motif that can become highly phosphorylated (for review, see Corden and Ingles 1992). Significantly, TBP interacts only with the nonphosphorylated form of RNA polymerase II (Usheva et al. 1992), which is the form known to enter the initiation complex. The form involved in transcription elongation is phosphorylated, suggesting that phosphorylation serves to release or disengage RNA polymerase II from the promoter (for review, see Dahmus and Dynan 1992), at least in part by disrupting the interaction with TBP (Usheva et al. 1992). A functional interaction between the heptad repeat and TBP is further suggested by the isolation in yeast of the $S R B 2$ gene as a dominant suppressor of truncation mutations in the heptad repeats of RNA polymerase II (Koleske et al. 1992). The allele specificity of this suppressor indicates that it is involved in the same function as the heptad repeat, and SRB2 interacts physically with TBP.

In addition to interacting with the general transcription factors IIA, IIB, and RNA polymerase II, TBP interacts with several factors termed $\mathrm{NC1}, \mathrm{NC2}$, and Dr1 (Meisterernst et al. 1991; Meisterernst and Roeder 1991; Inostroza et al. 1992). NC1 and NC2 have not been purified to homogeneity, but Drl is a $19-\mathrm{kD}$ protein whose corresponding cDNA has been cloned (Inostroza et al. 1992). These activities have a negative effect on core promoter function and interfere with the binding of TFIIA. Thus, phosphorylated Drl can associate stably with TBP on a TATA box and displace TFIIA. Dephosphorylated Drl cannot associate stably with TBP but can join a TFIIA-TBP-TATA box complex and preclude the association of TFIB with the preinitiation complex (Inostroza et al. 1992). Together, these observations define TBP as a target for positive and negative regulation of initiation complex assembly.

\section{Basal transcription from TATA-less RNA polymerase II mRNA promoters}

Transcription from TATA-less RNA polymerase II mRNA promoters depends on the Inr, which overlaps the transcriptional start site. One of the most extensively characterized Inrs is that of the lymphocyte-specific terminal deoxynucleotidyltransferase (TdT) promoter (Smale and Baltimore 1989), but Inrs are also present in a number of other TATA-less promoters as well as in some TATA box-containing promoters including the adenovirus 2 major late (Ad2 ML), Ad2 IVa2, and Ad2-associated virus $P 5$ promoters (Smale and Baltimore 1989; Carcamo et al. 1990; Seto et al. 1991; O'SheaGreenfield and Smale 1992; for review, see Weis and Reinberg 1992). However, not all Inrs share sequence homology, suggesting that there exist different families of Inrs functioning through different trans-acting factors.

Several TATA-less promoters, including the TdT promoter, contain Spl-binding sites that greatly stimulate transcription from the Inr (Smale and Baltimore 1989; Pugh and Tjian 1991). Nevertheless, the TdT Inr by itself is sufficient to direct basal levels of transcription. Similarly, the Inrs in the Ad2 ML, IVa2, and Ad2-associated virus $\mathrm{P} 5$ promoters can direct basal levels of transcription in the absence of the TATA box and any upstream activator element (Smale and Baltimore 1989; Carcamo et al. 1991; Seto et al. 1991; O'Shea-Greenfield and Smale 1992). All of these Inrs must therefore be capable of directing, albeit inefficiently, the assembly of the initiation complex. How is this accomplished?

In the model shown in Figure 5,E-G, a specific Inrbinding protein $(\mathrm{IBP})$ first binds to the Inr and thus replaces the DNA-binding function of TBP in nucleating the initiation complex (Fig. 5E). Several IBPs have been described. The Ad2 IVa2 and ML Inrs are recognized by a $120-\mathrm{kD}$ protein termed TFII-I (Roy et al. 1991), and the Ad2-associated virus P5 Inr is recognized by the YY1 protein (also termed $\delta$, NF-E1, or UCRBP; for review, see Weis and Reinberg 1992), which is required for efficient transcription in vitro (Seto et al. 1991; Shi et al. 1991). The order of entry of the next factors is not known, but TBP, TFIIB, RNA polymerase II, and TFIIF together can associate with the Ad2 ML Inr even in the absence of an IBP (Carcamo et al. 1991), suggesting that they enter the initiation complex simultaneously (Fig. 5F). As in TATA-containing promoters, TFIE, TFIIH, and TFIIJ presumably then join the initiation complex (Fig. 5G). Although the protein-protein interactions involved in this process remain to be characterized, the observations that TBP can bind weakly to the -30 region of several TATA-less promoters, including the TdT promoter (Wiley et al. 1992), and that insertion of a TATA box upstream of an Inr invariably augments transcription efficiency (Smale and Baltimore 1989; Carcamo et al. 1991) suggest that TBP is positioned similarly in initiation complexes formed on TATA-containing and TATA-less promoters (Fig. 5, cf. D and G), and is recruited more efficiently when a high-affinity site, the TATA box, is present. This, in turn, suggests that the interactions between TBP and other general transcription factors such as TFIIB and RNA polymerase II are similar on TATAcontaining and TATA-less promoters.

Although the Ad2 ML Inr (in the absence of the ML TATA box) can support basal transcription with both TBP and TFIID (Carcamo et al. 1991), the TdT Inr requires TFIID (Smale et al. 1990; Pugh and Tjian 1991; Zhou et al. 1992). Thus, in TATA-less promoters, the TFIID TAFs may stabilize the initiation complex, perhaps by contacting DNA in the Inr region. Purified TFIID 
Table 1. Structure and function studies of TBP

\begin{tabular}{|c|c|c|c|c|c|}
\hline Reference & $\begin{array}{l}\text { Interaction } \\
\text { or process } \\
\text { affected }\end{array}$ & Organism & $\begin{array}{l}\text { Position of } \\
\text { mutation, } \\
\text { deletion, }{ }^{\star} \text { or } \\
\text { region sufficient } \\
\text { for interaction }{ }^{\star}\end{array}$ & $\begin{array}{l}\text { Corresponding } \\
\text { position in } \\
\text { Arabidopsis } \\
\text { TBP-2 }\end{array}$ & $\begin{array}{l}\text { Location } \\
\text { in structure }\end{array}$ \\
\hline Reddy and Hahn (1991) & DNA binding & S. cerevisiae & $\begin{array}{l}\text { V71E } \\
\text { R105C } \\
\text { T112K } \\
\text { F99L } \\
\text { F116L } \\
\text { F116L } \\
\text { F116Y } \\
\text { R196C } \\
\text { V203K } \\
\text { F207L } \\
\text { F207Y }\end{array}$ & $\begin{array}{l}\text { V29 } \\
\text { R63 } \\
\text { T70 } \\
\text { [ F57 } \\
\text { F74 } \\
\text { F74 } \\
\text { F74 } \\
\text { R154 } \\
\text { V161 } \\
\text { F165 } \\
\text { F165 }\end{array}$ & $\begin{array}{l}\text { S1 } \\
\text { S3 } \\
\text { S4 } \\
\text { between S2 and S3 } \\
\text { S4 } \\
\text { S4 } \\
\text { S4 } \\
\text { S3' } \\
\text { S4' } \\
\text { S4' } \\
\text { S4' }\end{array}$ \\
\hline Yamamoto et al. (1992) & DNA binding & S. cerevisiae & $\begin{array}{l}\text { L67K } \\
\text { L76K } \\
\text { L80K } \\
\text { L82K } \\
\text { K110L } \\
\text { L114K } \\
\text { K120L } \\
\text { K127L } \\
\text { L172K } \\
\text { L175K } \\
\text { L193K } \\
\text { K201L } \\
\text { L204K } \\
\text { L205K } \\
\text { K211L } \\
\text { L214K } \\
\text { K218L } \\
\text { L234K }\end{array}$ & $\begin{array}{l}\text { L25 } \\
\text { L34 } \\
\text { L38 } \\
\text { L40 } \\
\text { K68 } \\
\text { L72 } \\
\text { K78 } \\
\text { K85 } \\
\text { L130 } \\
\text { L133 } \\
\text { L151 } \\
\text { K159 } \\
\text { L162 } \\
\text { L163 } \\
\text { K169 } \\
\text { I172 } \\
\text { K176 } \\
\text { L192 }\end{array}$ & 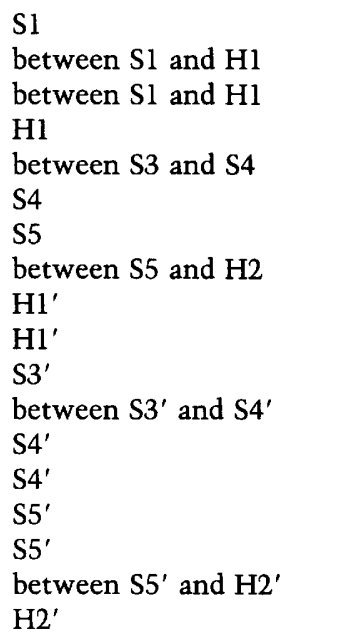 \\
\hline $\begin{array}{l}\text { Cormack and Struhl } \\
\text { (1992) }\end{array}$ & DNA binding & S. cerevisiae & $\begin{array}{l}\text { T111I } \\
\text { S136N }\end{array}$ & $\begin{array}{l}\text { T69 } \\
\text { A94 }\end{array}$ & $\begin{array}{l}\text { between S3 and S4 } \\
\mathrm{H} 2\end{array}$ \\
\hline Schultz et al. (1992) & DNA binding & S. cerevisiae & $\begin{array}{l}\text { P65S } \\
\text { T112K } \\
\text { I143N }\end{array}$ & $\begin{array}{l}\text { P23 } \\
\text { T70 } \\
\text { V101 }\end{array}$ & $\begin{array}{l}\mathrm{S} 1 \\
\mathrm{~S} 4 \\
\mathrm{H} 2\end{array}$ \\
\hline Poon et al. (1993) & DNA binding & S. cerevisiae & $\begin{array}{l}\text { L189P } \\
\text { F190Q } \\
\text { F190T }\end{array}$ & $\begin{array}{l}\text { L147 } \\
\text { F148 } \\
\text { F148 }\end{array}$ & $\begin{array}{l}\text { between } \mathrm{S} 2^{\prime} \text { and } \mathrm{S} 3^{\prime} \\
\text { between } \mathrm{S} 2^{\prime} \text { and } \mathrm{S} 3^{\prime} \\
\text { between } \mathrm{S} 2^{\prime} \text { and } \mathrm{S} 3^{\prime}\end{array}$ \\
\hline $\begin{array}{l}\text { Strubin and Struhl } \\
(1992)\end{array}$ & $\begin{array}{l}\text { change in DNA binding } \\
\text { specificity } \\
\text { (TATAAA } \rightarrow \text { TGTAAA) }\end{array}$ & S. cerevisiae & {$\left[\begin{array}{l}\mathrm{I} 194 \mathrm{~F} \\
\mathrm{~L} 205 \mathrm{~V} \\
\mathrm{~V} 203 \mathrm{~T}\end{array}\right.$} & {$\left[\begin{array}{l}\mathrm{I} 152 \\
\mathrm{~L} 163 \\
\mathrm{~V} 161\end{array}\right.$} & $\begin{array}{l}\text { S3' } \\
\text { S4' } \\
\text { S4' }\end{array}$ \\
\hline W. Lee et al. (1991) & interaction with E1A & human & $\mathrm{C} 221 \rightarrow \mathrm{E} 271^{\star \star}$ & $\mathrm{C} 81 \rightarrow \mathrm{E} 131$ & $\mathrm{~S} 5$ to $\mathrm{H}^{\prime}$ \\
\hline $\begin{array}{l}\text { Lieberman and Berk } \\
\text { (1991) }\end{array}$ & interaction with $\mathrm{Zta}$ & human & $\mathrm{L} 270 \rightarrow \mathrm{T} 339^{\star}$ & $\mathrm{L} 130 \rightarrow \mathrm{Q} 199$ & $\mathrm{Hl}^{\prime}$ to carboxyl terminus \\
\hline Eisenmann et al. (1992) & interaction with SPT3 & S. cerevisiae & $\begin{array}{l}\text { V851 } \\
\text { A86T } \\
\text { R171H } \\
\text { R171C } \\
\text { G174E } \\
\text { G174R } \\
\text { G174W } \\
\text { F177L } \\
\text { K239E }\end{array}$ & $\begin{array}{l}\text { I43 } \\
\text { A44 } \\
\text { R129 } \\
\text { R129 } \\
\text { G132 } \\
\text { G132 } \\
\text { G132 } \\
\text { Y135 } \\
\text { K197 }\end{array}$ & $\begin{array}{l}\mathrm{H} 1 \\
\mathrm{H} 1 \\
\text { between } \mathrm{Sl}^{\prime} \text { and } \mathrm{H}^{\prime} \\
\text { between } \mathrm{Sl}^{\prime} \text { and } \mathrm{H}^{\prime} \\
\mathrm{H}^{\prime} \\
\mathrm{H} 1^{\prime} \\
\mathrm{H} 1^{\prime} \\
\mathrm{H} 1^{\prime} \\
\text { carboxyl terminus }\end{array}$ \\
\hline
\end{tabular}


Table 1. (Continued)

\begin{tabular}{|c|c|c|c|c|c|}
\hline Reference & $\begin{array}{l}\text { Interaction } \\
\text { or process } \\
\text { affected }\end{array}$ & Organism & $\begin{array}{l}\text { Position of } \\
\text { mutation, } \\
\text { deletion, }{ }^{\star} \text { or } \\
\text { region sufficient } \\
\text { for interaction * }\end{array}$ & $\begin{array}{l}\text { Corresponding } \\
\text { position in } \\
\text { Arabidopsis } \\
\text { TBP-2 }\end{array}$ & $\begin{array}{l}\text { Location } \\
\text { in structure }\end{array}$ \\
\hline Lee et al. (1992) & interaciton with TFIIA & S. cerevisiae & $\begin{array}{l}\mathrm{K} 138 \mathrm{~L} \\
\mathrm{~K} 145 \mathrm{~L}\end{array}$ & $\begin{array}{l}\text { K96 } \\
\text { K103 }\end{array}$ & $\begin{array}{l}\mathrm{H} 2 \\
\mathrm{H} 2\end{array}$ \\
\hline $\begin{array}{l}\text { Buratowski and Zhou } \\
\text { (1992a) }\end{array}$ & interaction with TFIIA & S. cerevisiae & $\begin{array}{l}{\left[\begin{array}{l}\mathrm{K} 133 \mathrm{~L} \\
\mathrm{~K} 138 \mathrm{~L}\end{array}\right.} \\
{\left[\begin{array}{l}\mathrm{K} 133 \mathrm{~L} \\
\mathrm{~K} 145 \mathrm{~L}\end{array}\right.}\end{array}$ & $\begin{array}{l}{\left[\begin{array}{l}\text { K91 } \\
\text { K96 }\end{array}\right.} \\
{\left[\begin{array}{l}\text { K91 } \\
\text { K103 }\end{array}\right.}\end{array}$ & $\begin{array}{l}\mathrm{H} 2 \\
\mathrm{H} 2 \\
\mathrm{H} 2 \\
\mathrm{H} 2\end{array}$ \\
\hline Ha et al. (1993) & interaction with TFIIB & human & $\mathrm{M} 202 \rightarrow \mathrm{C} 221^{*}$ & $\mathrm{M} 62 \rightarrow \mathrm{C} 81$ & S3 to S5 \\
\hline $\begin{array}{l}\text { Cormack and Struhl } \\
\text { (1992) }\end{array}$ & Pol I, II, III transcription & S. cerevisiae & $\begin{array}{l}\text { T111I } \\
\text { S136N }\end{array}$ & $\begin{array}{l}\text { T69 } \\
\text { A94 }\end{array}$ & $\begin{array}{l}\text { between S3 and S4 } \\
\mathrm{H} 2\end{array}$ \\
\hline Schultz et al. (1992) & $\begin{array}{l}\text { Pol I, II, III transcription } \\
\text { Pol II, III transcription, } \\
\text { Pol I OK } \\
\text { Pol II transcription, Pol I, } \\
\text { III OK }\end{array}$ & S. cerevisiae & $\begin{array}{l}\text { I143N } \\
\text { P65S } \\
\text { T112K }\end{array}$ & $\begin{array}{l}\text { V101 } \\
\text { P23 } \\
\text { T70 }\end{array}$ & $\begin{array}{l}\mathrm{H} 2 \\
\mathrm{~S} 1 \\
\mathrm{~S} 4\end{array}$ \\
\hline $\begin{array}{l}\text { Buratowski and Zhou } \\
\text { (1992b) }\end{array}$ & $\begin{array}{l}\text { Pol III (interaction with } \\
\text { BRF) }\end{array}$ & & $\begin{array}{l}\text { K133L } \\
\text { K138L } \\
\text { K145L }\end{array}$ & $\begin{array}{l}\text { K91 } \\
\text { K96 } \\
\text { K103 }\end{array}$ & $\begin{array}{l}\mathrm{H} 2 \\
\mathrm{H} 2 \\
\mathrm{H} 2\end{array}$ \\
\hline $\begin{array}{l}\text { Colbert and Hahn } \\
\text { (1992) }\end{array}$ & $\begin{array}{l}\text { Pol III (interaction with } \\
\text { BRF) }\end{array}$ & & P65S & $\mathrm{P} 23$ & $\mathrm{~S} 1$ \\
\hline Poon et al. (1993) & $\begin{array}{l}\text { Pol I, II, III transcription } \\
\text { Pol II transcription (Pol I, } \\
\text { III diminished) } \\
\text { Pol I, II transcription (Pol } \\
\text { III diminished) }\end{array}$ & S. cerevisiae & $\begin{array}{l}\text { L189P } \\
\text { E188N } \\
\text { E188Y } \\
\text { E188P } \\
\text { F190Q }\end{array}$ & $\begin{array}{l}\text { L147 } \\
\text { E146 } \\
\text { E146 } \\
\text { E146 } \\
\text { F148 }\end{array}$ & $\begin{array}{l}\text { between S2' and S3' } \\
\text { between S2' and S3' } \\
\text { between S2' and S3' } \\
\text { between S2' and S3' } \\
\text { between S2' and S3' }\end{array}$ \\
\hline
\end{tabular}

protects the Ad2 ML promoter from DNase I digestion up to position +23 , whereas it protects the $\mathrm{E} 4$ promoter, which does not have a strong Inr region, only over the TATA box (Zhou et al. 1992 and references therein).

\section{Basal transcription from RNA polymerase II SnRNA promoters}

In the vertebrate snRNA promoters, the presence of a TATA box determines selection of RNA polymerase III over RNA polymerase II (see Fig. 2; Mattaj et al. 1988; Lobo and Hernandez 1989), and the RNA polymerase II snRNA promoters seemed therefore good candidates for TBP-independent promoters. However, recent experiments (Sadowski et al. 1993) have shown that transcription from the RNA polymerase II human U1 and U2 snRNA promoters requires TBP as part of a TBP-containing complex, termed the snRNA activating protein complex or $\mathrm{SNAP}_{c}$, which binds specifically to the PSE (Fig. $5 \mathrm{H}$ ) and presumably recruits at least some of the general transcription factors that are part of initiation complexes assembled on mRNA promoters (Fig. 5I).
$\mathrm{SNAP}_{\mathrm{c}}$ displays two properties that distinguish it from other TBP-containing complexes. First, unlike TFIID, SL1, and TFIIIB, which either recognize the TATA box or have little or no affinity for specific DNA sequences, SNAP $_{c}$ binds specifically to the PSE. Thus, the TAFs in $\mathrm{SNAP}_{\mathrm{c}}$ essentially reprogram the binding specificity of TBP and direct it to a sequence that is unrelated to a TATA box. Second, SNAP $_{c}$ appears to be also required for transcription from RNA polymerase III snRNA promoters (see below) and may therefore be involved in transcription by two different RNA polymerases (Sadowski et al. 1993).

\section{Activation of TATA-containing mRNA promoters}

Whereas the TBP subunit of TFIID is sufficient to direct the assembly of the basal RNA polymerase II transcription complex in vitro, it is not capable of mediating activation by different types of upstream DNA-binding proteins, including Spl, upstream stimulatory factor (USF), and proline-rich and acidic activators (Hoey et al. 1990; Hoffman et al. 1990b; Peterson et al. 1990; Pugh 


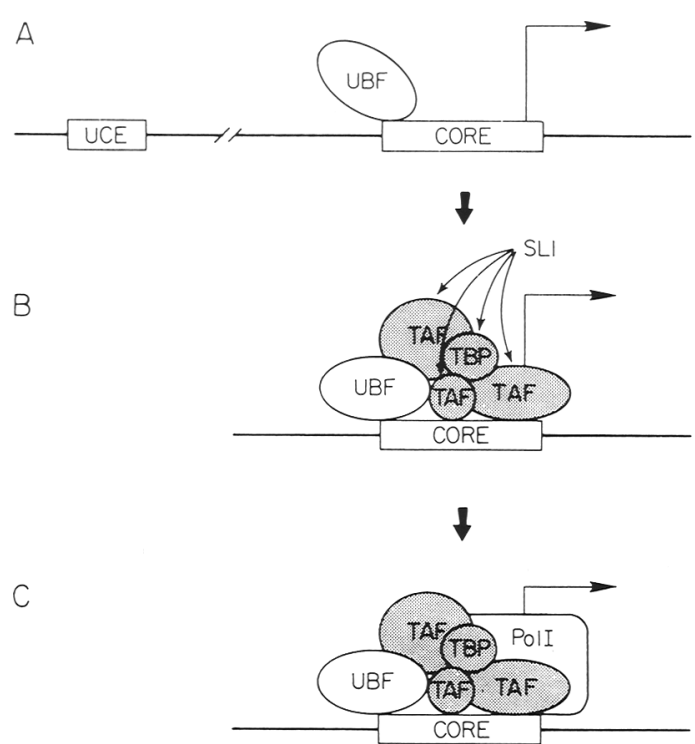

Figure 4. Model for the assembly of the mammalian RNA polymerase I initiation complexes. The binding of UBF to the promoter $(A)$ is stabilized by the binding of SL1 $(B)$, which consists of TBP and three TAFs (shaded). Which SL1 subunit contacts DNA is not known, and the representation of two TAFs binding to the core is arbitrary. UBF and SL1 then recruit RNA polymerase $\mathrm{I}(C)$.

and Tiian 1990; Smale et al. 1990; Tanese et al. 1991; J. White et al. 1991, 1992). In contrast, the TFIID fraction can sustain trans-activation in vitro, suggesting that additional proteins present in the TFIID fraction, which have been termed coactivators, are required for transactivator function (Peterson et al. 1990; Pugh and Tjian 1990). Similarly, in yeast, factors that have been termed mediators (Kelleher et al. 1990; Flanagan et al. 1991) or adaptors (Berger et al. 1990, 1992) are required for activated but not basal transcription.

During purification of both Drosophila and HeLa TFIID, TBP and coactivator activities copurify, suggesting that at least part of the coactivator function is provided by the TFIID TAFs (Pugh and Tjian 1990; Dynlacht et al. 1991). Drosophila TFID consists of TBP and at least seven TAFs (Dynlacht et al. 1991; Hoey et al. 1993), whereas human TFIID consists of TBP and at least eight TAFs (Tanese et al. 1991; Takada et al. 1992; Zhou et al. 1992, 1993). Three of the TFIID TAFs have been cloned-an 80- and a 110-kD TAF from Drosophila $\left(\mathrm{dTAF}_{\mathrm{II}} 80\right.$ and $\left.\mathrm{dTAF}_{\mathrm{II}} 110\right)$ (Dynlacht et al. 1993; Hoey et al. 1993) and a 250-kD TAF from both Drosophila $\left(\mathrm{dTAF}_{\mathrm{II}}{ }^{250)}\right.$ (Kokubo et al. 1993; Weinzierl et al. 1993) and humans $\left(\mathrm{hTAF}_{\mathrm{II}}\right.$ 250) (Hisatake et al. 1993; Ruppert et al. 1993). Both $\mathrm{dTAF}_{\mathrm{II}} 250$ and $\mathrm{hTAF}_{\mathrm{II}} 250$ contact TBP directly (Takada et al. 1992; Hisatake et al. 1993; Ruppert et al. 1993; Weinzierl et al. 1993; Zhou et al. 1993), whereas $\mathrm{dTAF}_{\mathrm{II}} 80$ and $\mathrm{dTAF}_{\mathrm{II}} 110$ do not appear to interact directly with TBP. dTAF $_{\text {II }} 110$ does, however, bind to $\operatorname{dTAF}_{\text {II }} 250$ (Weinzierl et al. 1993). In addition, it seems to contact the trans-activator Sp1 (Hoey et al. 1993), because it is retained on Spl columns and interacts with Spl in vivo in the two-hybrid assay of Fields and Song (1989). Because Spl does not appear to interact directly with TBP (Hoey et al. 1993), and because a complex consisting of $\mathrm{dTAF}_{\mathrm{II}} 110, \mathrm{dTAF}_{\mathrm{II}} 250$, and TBP can mediate
Figure 5. Model for the assembly of basal RNA polymerase II initiation complexes on TATA-containing and TATA-less RNA polymerase II mRNA promoters and on RNA polymerase II snRNA promoters. On TATA-containing mRNA promoters, TBP binds the DNA first $(A)$, perhaps with TFIIA, followed by TFIIB $(B)$ and the RNA polymerase II-TFIIF complex $(C)$. TBP interacts directly with these three factors. TFIIE, TFIIH, and TFIIJ then join the complex $(D)$. On TATA-less mRNA promoters, the assembly of the initiation complex is thought to start with the binding of an Inr-binding protein (IBP) to the $\operatorname{Inr}(E)$. This event allows the recruitment of TBP or TFIID, TFIIB, and the RNA polymerase IITFIIF complex $(F)$, most probably followed by TFIIE, TFIIH, and TFIIJ $(G)$ as in initiation complexes formed on TATA boxes. On snRNA promoters, TBP is recruited to the PSE as part of $\operatorname{SNAP}_{\mathrm{c}}(H)$. TBP is arbitrarily represented as interacting with the DNA through TAFs; it is not known whether TBP contacts the DNA directly. Once bound to the DNA, $\mathrm{SNAP}_{\mathrm{c}}$ may recruit general RNA polymerase II transcription factors $(I)$.

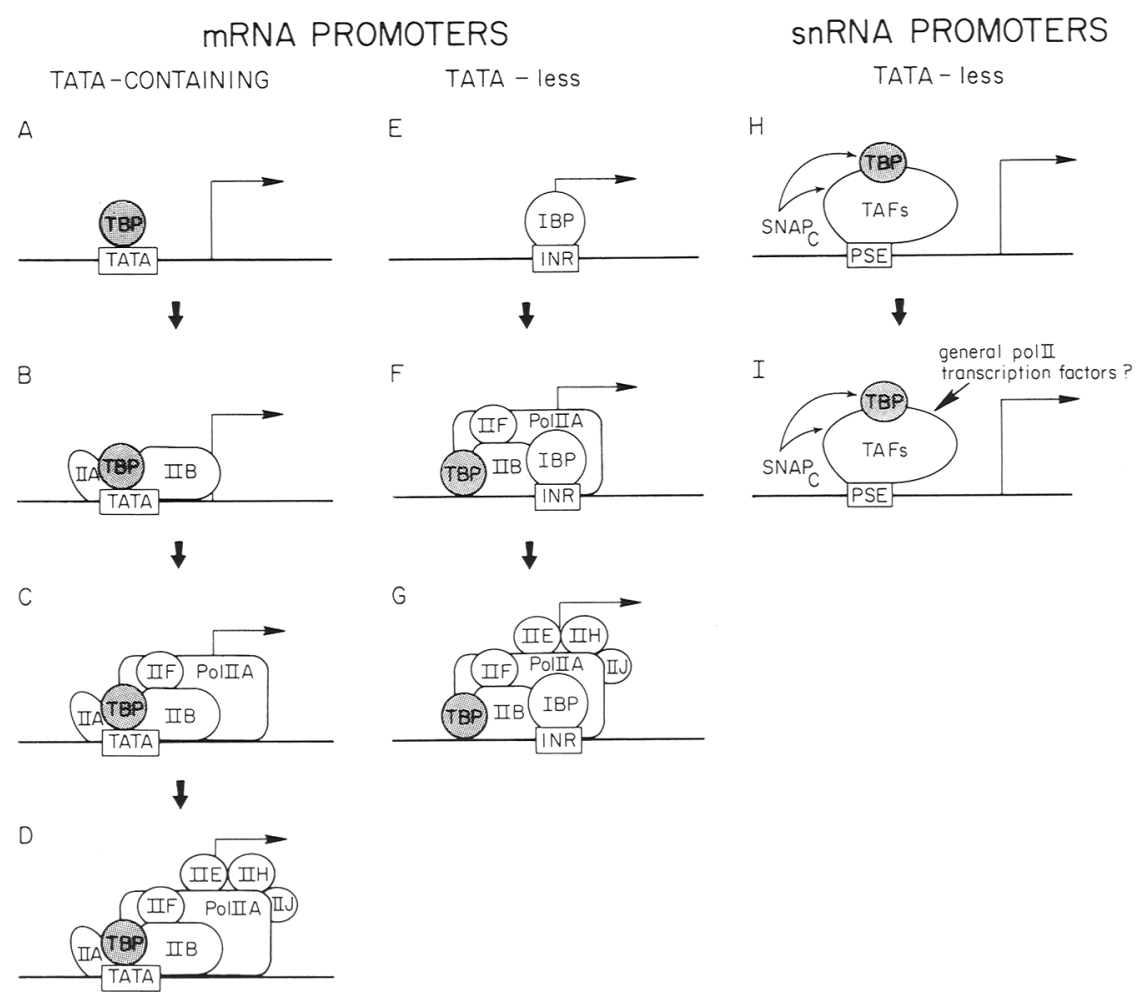


partial activation by $S p 1, \operatorname{dTAF}_{\mathrm{II}} 110$ and $\mathrm{dTAF}_{\mathrm{II}} 250$ appear to function as coactivators for Spl by bridging Spl with TBP, as shown in Figure 6 (Hoey et al. 1993; Weinzierl et al. 1993). $\mathrm{hTAF}_{\mathrm{II}} 250$ is identical and $\mathrm{dTAF}_{\mathrm{II}} 250$ is related to the human protein CCG1. CCG1 was identified as a gene product capable of overcoming $G_{1}$ arrest in a temperature-sensitive cell line maintained at the nonpermissive temperature and is therefore implicated in regulation of the cell cycle (Sekiguchi et al. 1988, 1991). This suggests that a domain of TAF-250 may be involved in activation of genes that control cell cycle progression.

An unresolved question is whether RNA polymerase II transcription of mRNA-encoding genes uses a unique TFIID complex or several subtle variants. In a stable HeLa cell line in which a large proportion of the endogenous TBP carries an epitope tag at its amino terminus, TFIID can be purified to apparent homogeneity by immunoaffinity chromatography with a monoclonal antibody directed against the tag. Such a TFIID preparation contains eight major polypeptides in addition to TBP, gives rise to a single complex in a mobility shift assay when incubated with a TATA-containing DNA probe, and can sustain trans-activation by a number of factors including an artificial acidic activator (GAL4-AH; see Giniger and Ptashne 1987), the Zta activator of EpsteinBarr virus, a GAL4-E1A fusion protein, and Spl (Zhou et al. 1992, 1993). These observations prompted Zhou et al. (1992) to suggest that the phosphocellulose D fraction (see Fig. 1) contains a single type of complex involved in RNA polymerase II transcription, which mediates transactivation by diverse activators. However, Brou et al. (1993) report that at least two TFIID-like complexes can be separated chromatographically, one of which mediates trans-activation by three different activators while the other mediates trans-activation by only one of the three activators. Because no unique properties have been assigned to the latter complex, it may just represent a partial TFIID complex that arises during purification. Nevertheless, it is difficult to exclude the existence of low-abundance TFIID-related complexes involved in transcription of subsets of RNA polymerase II mRNA promoters.

Not all coactivator activities are tightly associated with TBP. For example, an activity termed upstream stimulatory activity (USA) and required for maximal trans-activation by Spl and USF (Meisterernst et al. 1991), as well as a coactivator activity that increases trans-activation by the serum response factor and GAL4-VP16 (Zhu and Prywes 1992), can be separated from TFIID chromatographically. Furthermore, in yeast, there appears to be no stable TFIID complex because TBP

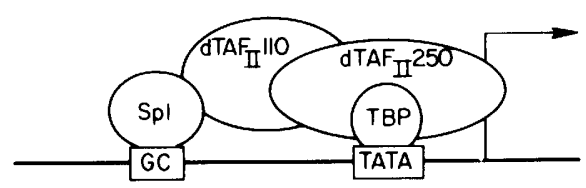

Figure 6. Interactions between $\mathrm{TBP}, \operatorname{dTAF}_{\mathrm{II}} 250, \mathrm{dTAF}_{\mathrm{II}} 110$, and $\mathrm{Spl}$. purifies as a single polypeptide (Buratowski et al. 1988; Cavallini et al. 1989). Putative functional equivalents of TAFs, such as the coactivator required for stimulation of transcription by the acidic activators GAL4-VP16 and GCN4 (Flanagan et al. 1991; Berger et al. 1992) or SPT3, an extragenic suppressor of the TBP mutation spt15-21 that may be required for transcriptional activation of a subset of RNA polymerase II genes (Eisenmann et al. 1992), may associate only transiently with TBP.

\section{Mechanisms for activation of RNA polymerase II transcription}

Several steps in the assembly of the initiation complex are potential targets for regulation by trans-activators. Trans-activators may stimulate transcription initiation by facilitating the binding of TBP to the TATA box, which in turn may accelerate the recognition of the promoter by the other general transcription factors, or by stabilizing the binding of TBP to weak TATA boxes, which may increase the number of competent initiation complexes. They may also act at steps subsequent to the binding of TBP to the DNA. At least in vitro, TFIID stays stably bound to the Ad2 ML promoter after departure of the RNA polymerase whereas TFIIB and TFIIE can exchange from one template to another, suggesting that the half-life of their association is short (Van Dyke et al. 1988,1989 ). If this holds in vivo, facilitating the binding of TBP to high-affinity TATA boxes, such as the Ad2 ML TATA box, should play a role only during the initial activation of the gene and may be more important for assembly of initiation complexes on chromatin than for assembly on the naked DNA templates generally used in in vitro transcription assays. In contrast, stabilizing the binding of TBP to low-affinity TATA boxes or increasing the efficiency of later steps in the assembly of the initiation complex should play a role at each round of transcription. It seems likely that each of these steps is regulated, but we know very little about the specific roles of activators and coactivators in these processes.

Coactivators have been proposed to function by bridging UBFs with TBP (Pugh and Tiian 1990), and the observation that TAF-110 interacts with Spl (Hoey et al. 1993) is consistent with this view (see Fig. 6). However, many other activators can interact directly with TBP, including the viral activators VP16 from herpes simplex virus, Ad2 E1A, Epstein-Barr virus Zta, and cytomegalovirus immediate early 2 protein (IE2), as well as the cellular activator/repressor p53 (Stringer et al. 1990; Ingles et al. 1991; Horikoshi et al. 1991; Lee et al. 1991; Lieberman and Berk 1991; Hagemeier et al. 1992; Seto et al. 1992; Truant et al. 1993). VP16 also binds to TFIIB, and this interaction is even stronger than that with TBP (Lin and Green 1991). These interactions are likely to be functionally relevant, because they are weakened by certain mutations in the activation domains of these proteins. Although in most cases their role in activation of transcription is not known, there are two examples where such interactions appear to reduce the off rate of the contacted general transcription factor. First, the Zta 
trans-activator decreases the off rate of TBP, especially on weak TATA boxes, and this effect is dependent on the Zta activation domain (Lieberman and Berk 1991). Curiously, the presence of Zta does not stabilize TBP association when an excess of competitor oligonucleotides is added to the binding reaction, indicating that $Z$ ta reduces TBP dissociation upon dilution but not intersegment transfer (Lieberman and Berk 1991). Second, although the role of the VP16-TBP interaction has not been defined, the VP16-TFIIB interaction is likely to stabilize the association of TFIIB with the initiation complex, as another acidic activator, GAL4-AH, renders a partial initiation complex containing TFIID and TFIIB resistant to dilution (Lin and Green 1991).

Even though Zta can stabilize the binding of TBP to the TATA box in the absence of any other factor, transcriptional activation by $\mathrm{Zta}$ requires TAFs as coactivators (Lieberman and Berk 1991; Zhou et al. 1992). Similarly, despite the direct interactions between E1A and TBP or between VP16 and TBP or TFIIB, activation by both E1A (Zhou et al. 1992) and VP16 (Flanagan et al. 1991; Berger et al. 1992; White et al. 1992) requires coactivators. This suggests that in these cases the coactivators are not involved in bridging the activator with TBP but, rather, exert their effect at a step subsequent to the binding of TBP and, in the case of VP16, TFIIB. VP16 can activate transcription at a step subsequent to the recruitment of TBP and TFIIB into the initiation complex in a coactivator (or TIFs for transcriptional intermediary factors)-dependent manner (White et al. 1992). Thus, activators participate in a large number of proteinprotein interactions and appear to act at several steps during transcription initiation. This is consistent with their ability to work synergistically even when their binding sites are saturated (Carey et al. 1990; Lin et al. 1990; for review, see Herschlag and Johnson 1993).

\section{Activated transcription from TATA-less mRNA promoters}

TATA-less mRNA promoters often contain Spl-binding sites and are strongly activated by $\mathrm{Spl}$. As for TATAcontaining RNA polymerase II promoters, the TFIID complex, but not TBP alone, can mediate this activation (Pugh and Tjian 1990, 1991; Smale et al. 1990; Zhou et al. 1992). However, the requirements for activation of TATA-less and TATA-containing promoters differ. In a heat-treated nuclear extract, Spl activation of a TATAcontaining, but not a TATA-less, promoter is restored by addition of recombinant TBP, suggesting that activation of TATA-less promoters specifically requires a heat labile factor, referred to as the tethering factor (Pugh and Tiian 1990, 1991). The tethering factor appears to be a $\mathrm{TAF}$, because it is present in highly purified preparations of TFIID (Zhou et al. 1993). Thus, TATA-containing and TATA-less promoters may use subtypes of the TFIID complex with slightly different compositions of TAFs, or they may use different domains of a single TFIID complex.
Function of the nonconserved amino-terminal domain of $T B P$

The function or (functions) of the nonconserved aminoterminal domain of TBP remains a mystery. The carboxy-terminal domain of TBP is sufficient to mediate transcriptional activation by acidic activators and $\mathrm{Sp} 1$ (Kelleher et al. 1992; Zhou et al. 1993), as well as retinoic acid-dependent trans-activation (Berkenstam et al. 1992). Furthermore, as summarized in Table 1, it is implicated in protein-protein interactions with the general transcription factors TFIIA and TFIIB, the yeast protein SPT3, and the trans-activators E1A, IE2, Zta, and probably VP16, as VP16 can interact with both human and yeast TBP (Stringer et al. 1990; Ingles et al. 1991). The TBP carboxy-terminal domain is also capable of restoring RNA polymerase III transcription in a heat-treated extract (White and Jackson 1992); and perhaps most striking, it is dispensable for viability in yeast (Cormack et al. 1991; Gill and Tjian 1991; Reddy and Hahn 1991; Zhou et al. 1991), although in some cases, the growth of yeast cells bearing only the carboxy-terminal domain of TBP was found to be severely impaired (Gill and Tjian 1991; Zhou et al. 1991). Because the amino-terminal domain of TBP is not conserved, it is likely to interact with transcription factors that are species specific. Transcription factors involved in transcription of rRNA and snRNA genes, whose promoters have diverged considerably across evolution, as well as viral transcription factors, are likely candidates.

\section{Role of TBP in transcription of RNA polymerase III promoters}

The RNA polymerase III promoters have been divided into three classes (for review, see Geiduschek and Kassavetis 1992). Classes 1 and 2 are gene-internal TATAless promoters and consist of the internal control region (ICR) of 5S rRNA genes and the A and B boxes of tRNA and 7 SL genes, Alu sequences, and viral genes such as the Ad2 VAI and VAII genes. Class 3 promoters are found in a number of vertebrate snRNA and cytoplasmic RNA genes, including the U6, 7SK, hYl and $\mathrm{hY} 3, \mathrm{Hl}$, and MRP/Th RNA genes (for review, see Hernandez 1992). They are located entirely upstream of the gene-coding sequences and are similar to the RNA polymerase II snRNA promoters except for the presence of a TATA box, which determines the RNA polymerase III specificity of the promoter (Fig. 2). Transcription from both the TATA-less and TATA-containing RNA polymerase III promoters requires TBP, although in different complexes.

\section{Transcription from TATA-less RNA polymerase III promoters}

RNA polymerase III transcription from the gene-internal class 1 and 2 promoters can be reconstituted by combi- 
nations of the $A, B$, and $C$ fractions, which contain TFIIIA, TFIIIB, and TFIIIC (Fig. 1) (for review, see Geiduschek and Kassavetis 1992; Gabrielsen and Sentenac 1991). Transcription of the 5S genes requires TFIIIA, TFIIIB, and TFIIIC. TFIIIA binds to the ICR, and this event allows the subsequent entry of TFIIIC and TFIIIB into the initiation complex. Transcription from the class 2 promoters does not require TFIIIA, because TFIIIC can bind directly to the $\mathrm{A}$ and $\mathrm{B}$ boxes and recruit TFIIIB. Although TFIIIB does not bind DNA on its own, in the context of the initiation complex it contacts DNA in a non-sequence-specific manner upstream of the transcriptional start site. In the yeast system, TFIIIB becomes tightly bound in an apparently nonionic interaction, such that it remains attached to the DNA under stringent conditions (high salt or heparin) that remove TFIIIA and TFIIIC. Remarkably, these partial initiation complexes can direct several rounds of RNA polymerase III transcription, indicating that once bound to the DNA, TFIIIB is sufficient to recruit RNA polymerase III (Kassavetis et al. 1990). This suggests that TFIIIB or at least a component of TFIIIB is present in every RNA polymerase III initiation complex.

The composition of TFIIIB has been controversial. Early reports identified mammalian (Waldschmidt et al. 1988) and yeast (Klekamp and Weil 1986) TFIIIB as a $60-\mathrm{kD}$ polypeptide, but yeast TFIIIB was subsequently separated into two components, termed TFIIIB' $^{\prime}$ and TFIIIB", which were shown to contain a 70- and a 90-kD polypeptide, respectively (Bartholomew et al. 1991; Kassavetis et al. 1991). From genetic and biochemical lines of evidence, we now know that TFIIIB also contains TBP.

In screening for extragenic suppressors of mutations in TBP or in a tRNA gene A box promoter element, three groups have independently isolated a yeast gene (TDS4/ PCF4/BRF1) that encodes a protein related to mammalian and yeast TFIIB (Buratowski and Zhou 1992b; Colbert and Hahn 1992; Lopez de Leon et al. 1992). This $67-\mathrm{kD}$ protein, hereafter referred to as $\mathrm{BRF}$, was then shown to correspond to the $70-\mathrm{kD}$ component of TFIIIB' (Kassavetis et al. 1992). The isolation of BRF as an allelespecific suppressor of temperature-sensitive TBP mutations suggested a direct interaction between these two proteins (Buratowski and Zhou 1992b; Colbert and Hahn 1992; see Table 1). TBP is present in the heparin-resistant TFIIIB-DNA complex (Buratowski and Zhou 1992b; Huet and Sentenac 1992; Kassavetis et al. 1992), and TFIIIB' activity can be fully reconstituted from recombinant BRF and TBP (Kassavetis et al.,1992). Because the 90-kD polypeptide reconstitutes TFIIIB $^{\prime \prime}$ activity, it seems that yeast TFIIIB consists of three polypetides: BRF1, TBP, and the $90-\mathrm{kD}$ polypeptide (Kassavetis et al. 1992).

Figure 7 shows the assembly of yeast TFIIIB on a tRNA promoter as determined by site-specific DNA-protein photo-cross-linking (Kassavetis et al. 1992). When TFIIIC binds to the A and B boxes of a tRNA gene, only one of five TFIIIC subunits ( $135 \mathrm{kD})$ projects upstream of the start site of transcription and is therefore likely to interact with TFIIIB (Bartholomew et al. 1991; see Fig.
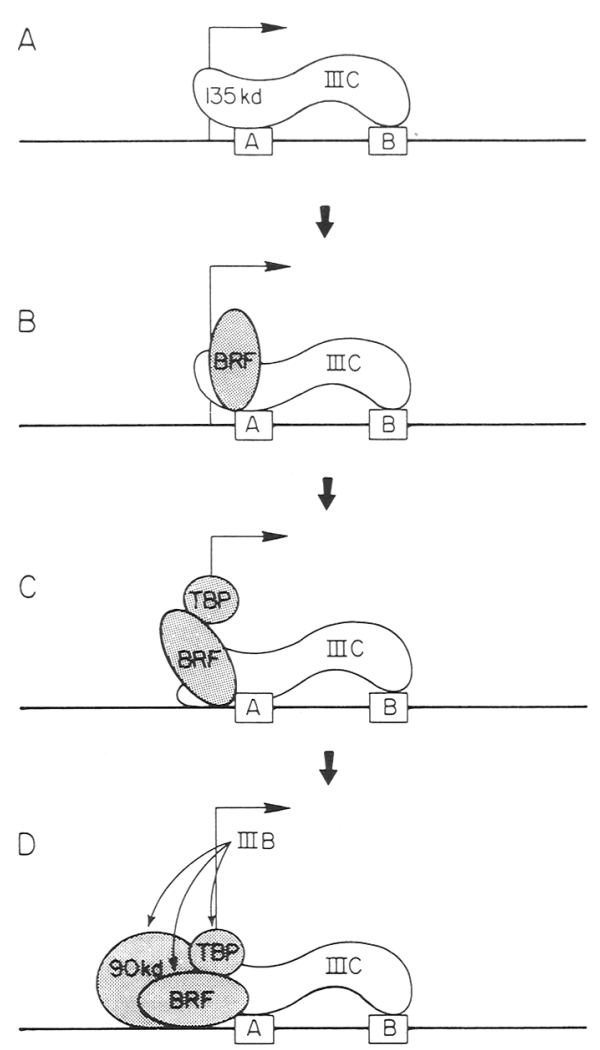

Figure 7. Assembly of a $S$. cerevisiae RNA polymerase III initiation complex on a class 2 promoter (adapted from Kassavetis et al. 1992). TFIIIC binds to the A and B boxes, with the $135-\mathrm{kD}$ subunit pointing upstream of the transcriptional start site $(A)$. TFIIIB (shaded), which is composed of BRF, TBP, and the 90-kD protein, can then enter the initiation complex. BRF interacts with the $135-\mathrm{kD}$ TFIIIC subunit $(B)$. TBP then joins the complex, and this induces a conformational change that brings the $135-\mathrm{kD}$ TFIIIC subunit and BRF in closer contact with the DNA (C). Finally, the $90-\mathrm{kD}$ subunit of TFIIIB locks the TFIIIB complex on the DNA $(D)$.

7A). BRF can bind to this complex, presumably through interaction with the $135-\mathrm{kD}$ TFIIIC subunit (Fig. 7B), and recruits TBP (Fig. $7 \mathrm{C}$ ). In the absence of TBP, the association of BRF with the initiation complex is weak, because BRF cannot be efficiently cross-linked to the DNA. However, upon the incorporation of TBP into the complex, both BRF and the TFIIIC $135-\mathrm{kD}$ subunit can be very efficiently cross-linked to the DNA, suggesting that TBP unmasks a BRF DNA-binding domain. It is striking that the interaction between TBP and TFIIB similarly allows TFIIB to bind to the DNA, in this case downstream of the transcriptional start site (Maldonado et al. 1990|; because BRF and TFIIB are related, their interaction with TBP may have been conserved (Kassavetis et al. 1992, Lopez de Leon et al. 1992). After TBP has joined the complex, the $90-\mathrm{kD}$ protein is recruited, and this event results in a weakening of the $135-\mathrm{kD}$ protein photo-cross-linking, a strengthening of BRF cross-linking, and the cross-linking of the $90-\mathrm{kD}$ protein (Fig. 7D). 
Concurrently with the studies on yeast TFIIIB, several groups showed that TBP is part of human TFIIIB (Lobo et al. 1992; Simmen et al. 1992; Taggart et al. 1992; White and Jackson 1992), but the exact polypetide composition of mammalian TFIIIB is still unknown. Taggart et al. (1992) immunopurified human TFIIIB with anti-TBP polyclonal antibodies and showed that it consists of TBP, one tightly associated polypetide (TAF-172), and one or several uncharacterized loosely associated polypetides (TAF-L). In the experiments of Lobo et al. (1992), the TFIIIB activity could be separated into two fractions, termed according to their elution profile on a mono $\mathrm{Q}$ column $0.38 \mathrm{M}$-TFIIIB and 0.48M-TFIIIB (see Fig. 1), which are both required for transcription of the Ad2 VAI gene. $0.38 \mathrm{M}$-TFIIIB contains TBP associated with a polypetide of $82 \mathrm{kD}$ and probably two additional polypetides of 150 and $54 \mathrm{kD}$, of which the large one is likely to correspond to TAF-172. It is not clear whether $0.48 \mathrm{M}$ TFIIIB corresponds to TAF-L.

An intriguing question is the relationship between B-TFIID, a TBP-containing complex purifed from the B fraction (Timmers and Sharp 1991; Timmers et al. 1992), and TFIIIB. B-TFIID has been purified extensively on the basis of its ability to support basal RNA polymerase II transcription and contains TBP and a $170-\mathrm{kD}$-associated polypetide, close in size to TAF-172. Interestingly, less pure fractions contain, in addition, an $80-\mathrm{kD}$ polypetide, close in size to the $82-\mathrm{kD}$ polypeptide found associated with TBP in $0.38 \mathrm{M}$-TFIIIB. The function of the pure complex in RNA polymerase III transcription has not been tested, but White and Jackson (1992) report that a fraction containing B-TFIID is active for basal RNA polymerase II but not RNA polymerase III transcription. Because B-TFIID has not been attributed any function different from that of TBP in RNA polymerase II transcription, it may represent a partial TFIIIB complex.

\section{Transcription from RNA polymerase III snRNA (TATA- containing) promoters}

The factors required for RNA polymerase III transcription of the human or mouse U6 gene include the B fraction, a PSE-binding factor present in the $\mathrm{C}$ fraction, and TBP (Lobo et al. 1991; Simmen et al. 1991; Waldschmidt et al. 1991; Sadowski et al. 1993). The PSE-binding factor required for U6 transcription cofractionates exactly over several columns with the TBP-containing complex $\mathrm{SNAP}_{c}$, suggesting that $\mathrm{SNAP}_{c}$ is required for transcription of both RNA polymerase II and III snRNA genes (Sadowski et al. 1993). Interestingly, reconstitution of $\mathrm{U} 6$ transcription requires TBP in addition to $\mathrm{SNAP}_{\mathrm{c}}$ and the B fraction (which provides TFIIIB and RNA polymerase III). This suggests that the U6 initiation complex contains at least two forms of TBP, one bound to the PSE as part of the SNAP complex and one bound to the TATA box (Fig. 8D) (Sadowski et al. 1993).

Because at least one component of TFIIIB $(0.38 \mathrm{M}-$ TFIIIB) is now known to contain TBP, an interesting question is whether the U6 requirement for the B frac- tion is for the same form of TFIIIB as the TATA-less RNA polymerase III promoters. At least in vitro, this is not the case. When extracts are immunodepleted with anti-TBP monoclonal antibodies (that do not recognize SNAP $_{\mathrm{c}}$, U6 transcription can be reconstituted by the addition of recombinant TBP, unlike VAI transcription, which requires the $0.38 \mathrm{M}$-TFIIIB complex (Lobo et al. 1992). A model for the assembly of mammalian RNA polymerase III initiation complexes on TATA-less and TATA-containing promoters is shown in Figure 8. Whereas in TATA-less RNA polymerase III genes, the TAFs in $0.38 \mathrm{M}$-TFIIIB allow the recruitment of TBP to the initiation complex by interactions with the TFIIICDNA complex (Fig. 8B), in TATA-containing RNA polymerase III promoters they are dispensable, because TBP can bind directly to the TATA box, presumably together with the SNAP complex (Fig. 8D). Which, then, is the active component required for $\mathrm{U} 6$ transcription in the $\mathrm{B}$ fraction? It appears to be the other component of TFIIIB (0.48M-TFIIIB), because U6 transcription can be reconstituted with a combination of the $\mathrm{C}$ fraction /which contains SNAP $_{c}$ and RNA polymerase III), a $0.48 \mathrm{M}-$ TFIIIB-containing fraction, and recombinant TBP (S.M. Lobo and N. Hernandez, unpubl.). Thus, TBP and SNAP probably recruit $0.48 \mathrm{M}$-TFIIIB (Fig. $8 \mathrm{E}$ ), and this allows the entry of RNA polymerase III into the initiation complex (Fig. 8F). The observation that the U6 initiation complex may contain two forms of TBP opens the possibility that other transcription complexes also contain several forms of TBP performing different functions. Perhaps the bewildering array of protein-protein interactions involving TBP can be distributed among different TBP molecules present in a single initiation complex.

The $S$. cerevisiae U6 promoter was first thought to be similar in structure to the human U6 promoter. The yeast U6-coding region contains a match to an A box but no consensus $\mathrm{B}$ box, and the $5^{\prime}$-flanking region contains a TATA box and an 11-nucleotide match to the human sequence that partially overlaps with the human U6 PSE (Brow and Guthrie 1988). Later experiments, however, identified a B box similar to the intragenic $B$ box of tRNA genes but located 120 nucleotides downstream of the coding region (Brow and Guthrie 1990). This B box is essential for transcription of the yeast U6 gene in vivo, greatly stimulates transcription in vitro, and relieves nucleosome repression of in vitro transcription (Brow and Guthrie 1990; Burnol et al. 1993). In addition, unlike in the human U6 gene, where the TATA box is essential for RNA polymerase III transcription, the yeast U6 TATA box plays a role in localizing the transcription start site but is not essential for transcription (Eschenlauer et al. 1993). Together, these results suggests that the complete yeast U6 promoter is quite similar to a tRNA promoter. Transcription of the yeast U6 gene requires RNA polymerase III, TFIIIC, and TFIIIB (Burnol et al. 1993). The TBP component of TFIIIB is essential (Margottin et al. 1991; Huet and Sentenac 1992), but unlike for the human U6 initiation complex, it is not clear that TBP enters the yeast $\mathrm{U} 6$ initiation complex differently than it does a tRNA initiation complex. 


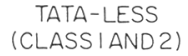

A

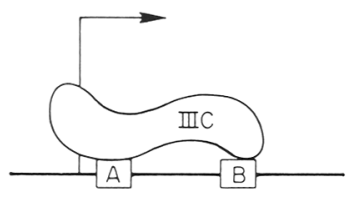

$\downarrow$

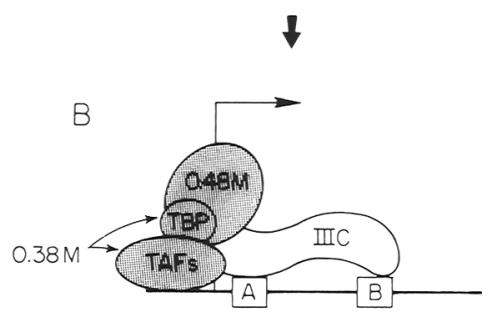

$\downarrow$

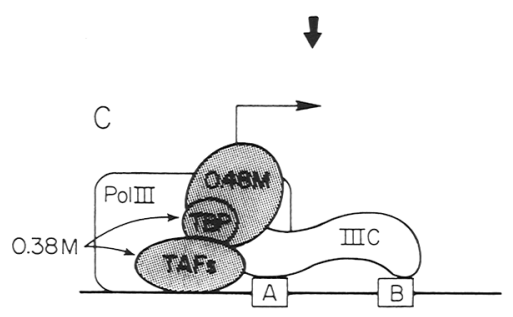

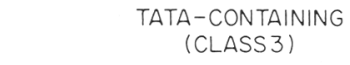

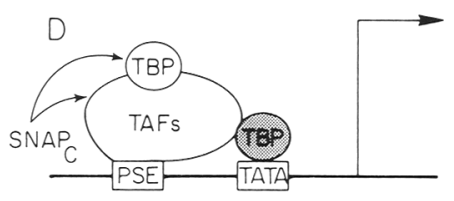

$\downarrow$

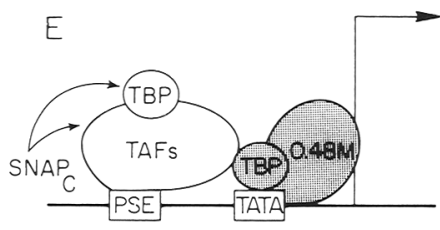

$\downarrow$

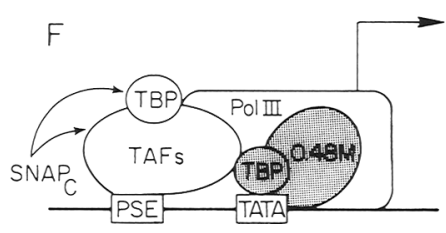

Figure 8. Assembly of a mammalian RNA polymerase III initiation complex on a TATA-less class 2 promoter and on a TATA-containing class 3 promoter. In TATA-less class 2 RNA polymerase III promoters, TFIIIC binds to the A and B boxes $(A)$, followed by TFIIIB $(B)$ and RNA polymerase III $(C)$. Two separable components of TFIIIB are required for transcription of TATA-less RNA polymerase III genes; $0.38 \mathrm{M}$-TFIIIB, a TBP-containing complex, and $0.48 \mathrm{M}$-TFIIIB. In TATA-containing RNA polymerase III promoters, TBP and SNAP $_{c}$ bind to the DNA first $(D)$ and presumably recruit $0.48 \mathrm{M}$-TFIIIB $(E)$, followed by RNA polymerase III $(F)$. Transcription of the TATA-containing RNA polymerase III genes does not require $0.38 \mathrm{M}$-TFIIIB. TFIIIB components are shaded.
Does TBP perform a common function in RNA polymerase $I, I I$, and III initiation complexes?

TBP was first characterized as an activity that binds to the TATA box of mRNA genes and nucleates the formation of an RNA polymerase II initiation complex. TBP is now known to participate in transcription initiation by all three RNA polymerases; and if it performs a constant function, it is certainly not binding to the TATA box. TBP enters initiation complexes formed on TATA-less promoters through protein-protein interactions, which in some cases seem to mask its DNA-binding domain. Thus, TAF-172, which is part of human TFIII, inhibits the binding of TBP to the TATA box (Taggart et al. 1992). As noted previously (Lobo et al. 1992), a dual mechanism to enter an initiation complex is not unique to TBP and may turn out to be a property shared by a large number of transcription factors. For example, TFIIIC is recruited to tRNA promoters by direct binding to the $\mathrm{A}$ and $\mathrm{B}$ boxes, but it is recruited to the $5 \mathrm{~S}$ promoters by proteinprotein interactions with TFIIIA.

It is surprising that the two mechanisms for recruitment of TBP are not segregated along the RNA polymerase specificities of promoters. Thus, there are TATAcontaining and TATA-less RNA polymerase II promoters, and TATA-containing and TATA-less RNA polymerase III promoters. Moreover, it appears that not all RNA polymerase II or RNA polymerase III promoters use the same TBP-containing complex. The initiation complexes formed on both TATA-containing and TATA-less RNA polymerase II mRNA promoters contain TFIID, but those formed on RNA polymerase II
snRNA promoters contain $\mathrm{SNAP}_{\mathrm{c}}$. And whereas the TBP-containing complex $0.38 \mathrm{M}$-TFIIIB is absolutely required for transcription of TATA-less RNA polymerase III genes, it can be replaced by TBP alone for basal transcription of the human U6 gene. Thus, the same RNA polymerase specificity can be achieved through different pathways.

The apparently universal presence of TBP in eukaryotic initiation complexes suggests that TBP was part of an early initiation complex that preceded the evolutionary divergence of the three RNA polymerases. Yet, whether TBP still has a conserved function in the contemporary RNA polymerase I, II, and III initiation complexes is not clear. It seems likely that additional transcription factors besides TBP are shared by different RNA polymerases. TFIIA has been implicated in transcription of RNA polymerase III genes (Meissner et al. 1993). It also seems likely that like BRF and TFIIB, other RNA polymerase I, II, and III transcription factors share regions of homologies. The interactions between TBP and such factors will then probably be conserved. Thus, RNA polymerase I, II, and III initiation complexes may differ in much more subtle ways than was originally suspected.

\section{Acknowledgments}

I thank E. Geiduschek, M. Green, S. Hahn, S. Jackson, F. Pugh, D. Reinberg, and their colleagues for communication of results prior publication. I also thank M. Gilman, W. Herr, M. Tanaka, and $W$. Tansey for comments on the manuscript. This work was 
funded by National Institute of Health grant ROIGM38810. N.H. is a Rita Allen Foundation Scholar.

\section{References}

Apsit, V., J.A. Freeberg, M.R. Chase, E.A. Davis, and S. Ackerman. 1993. Wheat TFIID TATA binding protein. Nucleic Acids Res. 21: 1494.

Bartholomew, B., G.A. Kassavetis, and E.P. Geiduschek. 1991. Two components of $S$. cerevisiae TFIIIB are stereospecifically located upstream of a tRNA gene and interact with the second largest subunit of TFIIIC. Mol. Cell. Biol. 11: 51815189.

Bell, S.P., M. Learned, H.-M. Jantzen, and R. Tjian. 1988. Functional cooperativity between transcription factors UBFl and SL1 mediates human ribosomal RNA synthesis. Science 241: 1192-1197.

Bell, S.P., H.-M. Jantzen, and R. Tjian. 1990. Assembly of alternative multiprotein complexes directs rRNA promoter selectivity. Genes \& Dev. 4: 943-954.

Berger, S.L., W.D. Cress, A. Cress, S.J. Triezenberg, and L. Guarente. 1990. Selective inhibition of activated but not basal transcription by the acidic activation domain of VP16: Evidence for transcriptional adaptors. Cell 61: 1199-1208.

Berger, S.L., B. Pina, N. Silverman, G.A. Marcus, J. Agapite, J.L. Regier, S.J. Triezenberg, and L. Guarente. 1992. Genetic isolation of ADA2: A potential transcriptional adaptor required for function of certain acidic activation domains. Cell 70: $251-265$.

Berkenstam, A., M. del Mar Vivanco Ruiz, D. Barettino, M. Horikoshi, and H.G. Stunnenberg. 1992. Cooperativity in transactivation between retinoic acid receptor and TFIID requires an activity analogous to E1A. Cell 69: 401-412.

Brou, C., S. Chaudhary, I. Davidson, Y. Lutz, J. Wu, J.-M. Egly, L. Tora, and P. Chambon. 1993. Distinct TFIID complexes mediate the effect of different transcriptional activators. EMBO J. 12: 489-499.

Brow, D.A. and C. Guthrie. 1988. Spliceosomal RNA U6 is remarkably conserved from yeast to mammals. Nature 334: 213-218.

-1990. Transcription of a yeast U6 snRNA gene requires a polymerase III promoter element in a novel position. Genes \& Dev. 4: 1345-1356.

Buratowski, S., S. Hahn, P.A. Sharp, and L. Guarente. 1988. Function of a yeast TATA element-binding protein in a mammalian transcription system. Nature 334: 37-42.

Buratowski, S. and P.A. Sharp. 1992. Initiation of transcription by RNA polymerase II. In Transcriptional regulation. Monograph 22 (ed. S. McKnight and K.R. Yamamoto) pp. 227-246. Cold Spring Harbor Laboratory Press, Cold Spring Harbor, New York.

Buratowski, S. and H. Zhou. 1992a. Transcription factor IID mutants defective for interaction with transcription factor IIA. Science 255: 1130-1132.

- 1992b. A suppressor of TBP mutations encodes an RNA polymerase III transcription factor with homology with TFIIB. Cell 71: 221-230.

Buratowski, S., S. Hahn, L. Guarente, and P.A. Sharp. 1989. Five intermediate complexes in transcription initiation by RNA polymerase II. Cell 56: 549-561.

Burnol, A.-F., F. Margottin, J. Huet, G. Almouzni, M.-N. Prioleau, M. Mechali, and A. Sentenac. 1993. TFIIIC relieves repression of U6 snRNA transcription by chromatin. Nature 362: 475-477.

Carcamo, J., E. Maldonado, P. Cortes, M.-H. Ahn, I.-Ha, Y. Ka- sai, J. Flint, and D. Reinberg. 1990. A TATA-like sequence located downstream of the transcription initiation site is required for expression of an RNA polymerase II transcribed gene. Genes \& Dev. 4: 1611-1622.

Carcamo, J., L. Buckbinder, and D. Reinberg. 1991. The initiator directs the assembly of a transcription factor IID-dependent transcription complex. Proc. Natl. Acad. Sci. 88: 8052-8056.

Carey, M., Y.-S. Lin, M.R. Green, and M. Ptashne. 1990. A mechanism for synergistic activation of a mammalian gene by GAL4 derivatives. Nature 345: 361-364.

Cavallini, B., J. Huet, J.L. Plassat. A. Sentenac, J.M. Egly, and P. Chambon. 1988. A yeast activity can substitute for the HeLa cell TATA box factor. Nature 334: 77-80.

Cavallini, B., I. Faus, H. Matthes, J.M. Chipoulet, B. Winsor, J.M. Egly, and P. Chambon. 1989. Cloning of the gene encoding the yeast protein BTF1Y, which can substitute for the human TATA box binding factor. Proc. Natl. Acad. Sci. 86: 9803-9807.

Colbert, T. and S. Hahn. 1992. A yeast TFIIB-related factor involved in RNA polymerase III transcription. Genes \& Dev. 6: 1940-1949.

Comai, L., N. Tanese, and R. Tjian. 1992. The TATA-binding protein and associated factors are integral components of the RNA polymerase I transcription factor, SL1. Cell 68: 965976.

Conaway, J.W., D. Reines, and R.C. Conaway. 1990. Transcription initiated by RNA polymerase II and transcription factors from liver: Cooperative interaction of transcription factor $\tau$ and $\epsilon$ in initial complex formation. J. Biol. Chem. 265: 7552-7558.

Conaway, J.W., J.P. Hanley, K.P. Garret, and R.C. Conaway. 1991. Transcription initiated by RNA polymerase II and transcription factors in liver: Structure and function of $\epsilon$ and т. J. Biol. Chem. 266: 7804-7811.

Corden, J.L. and C.J. Ingles. 1992. Carboxy-terminal domain of the largest subunit of eucaryotic RNA polymerase II. In Transcriptional regulation. Monograph 22 (ed. S. McKnight and K.R. Yamamoto), pp. 81-108, Cold Spring Harbor Laboratory Press, Cold Spring Harbor, New York.

Cormack, B.P. and K. Struhl. 1992. The TATA-binding protein is required for transcription by all three nuclear RNA polymerases in yeast cells. Cell 69: 685-696.

Cormack, B.P., M. Strubin, A.S. Ponticelli, and K. Struhl. 1991. Functional differences between yeast and human TFIID are localized to the highly conserved region. Cell 65: 341-348.

Cortes, P., O. Flores, and D. Reinberg. 1992. Factors involved in specific transcription by mammalian RNA polymerase II: Purification and analysis of transcription factor IIA and identification of transcription factor IIJ. Mol. Cell. Biol. 12: 413421.

Crowley, T.E., T. Hoey, J.-K. Liu, Y.N. Jan, L.Y. Jan, and R. Tjian. 1993. A new factor related to TATA-binding protein has highly restricted expression pattern in Drosophila. $\mathrm{Na}$ ture 361: 557-561.

Dahmus, M.E. and W.S. Dynan. 1992. Phosphorylation of RNA polymerase II as a transcriptional regulatory mechanism. In Transcriptional regulation. Monograph 22 (ed. S. McKnight and K.R. Yamamotol, pp. 281-313, Cold Spring Harbor Laboratory Press, Cold Spring Harbor, New York.

Dynlacht, B.D., T. Hoey, and R. Tjian. 1991. Isolation of coactivators associated with the TATA-binding protein that mediate transcriptional activation. Cell 66: 563-576.

Dynlacht, B.D., R.O.J. Weinzierl, A. Admon, and R. Tjian. 1993. The dTAF 80 subunit of Drosophila TFIID contains $\beta$-transducin repeats. Nature 363: 176-179.

Eisenmann, D.M., K.M. Arndt, S.L. Ricupero, J.W. Rooney, and 
F. Winston. 1992. SPT3 interacts with TFIID to allow normal transcription in Saccharomyces cerevisiae. Genes \& Dev. 6: 1319-1331.

Eschenlauer, J.B., M.W. Kaiser, V.L. Gerlach, and D.A. Brow. 1993. Architecture of a yeast U6 RNA gene promoter. Mol. Cell. Biol. 13: 3015-3026.

Fields, S. and O. Song. 1989. A novel genetic system to detect protein-protein interactions. Nature 340: 245-246.

Fikes, J.D., D.M. Becker, F. Winston, and L. Guarente. 1990. Striking conservation of TFIID in Schizosaccharomyces pombe and Saccharomyces cerevisiae. Nature 346: 291-294.

Flanagan, P.M., R.J. Kelleher III, M.H. Sayre, H. Tschochner, and R.D. Kornberg. 1991. A mediator required for activation of RNA polymerase II transcription in vitro. Nature 350: 436438.

Gabrielsen, O.S. and A. Sentenac. 1991. RNA polymerase III (C) and its transcription factors. Trends Biochem. Sci. 16: 412416.

Gasch, A., Hoffmann, A., Horikoshi, M., Roeder, R.G, and N. Chua. 1990. Arabidopsis thaliana contains two genes for TFIID. Nature 346: 390-394.

Geiduschek, E.P. and G.A. Kassavetis. 1992. RNA polymerase III transcription complexes. In Transcriptional regulation. Monograph 22 (ed. S.L. McKnight and K.R. Yamamoto), pp. 247-280. Cold Spring Harbor Laboratory Press, Cold Spring Harbor, New York.

Gill, G. and R. Tjian. 1991. A highly conserved domain of TFIID displays species specificity in vivo. Cell 65: 333-340.

Giniger, E. and M. Ptashne. 1987. Transcription in yeast activated by a putative amphipathic $\alpha$ helix linked to a DNA binding unit. Nature 330: 670-672.

Ha, I. S. Roberts, E. Maldonado, X. Sun, M. Green, and D. Reinberg. 1993. Multiple functional domains of human transcription factor IIB. Distinct interactions with two general transcription factors and RNA polymerase II. Genes $\&$ Dev. 7: 1021-1032.

Haass, M.M. and G. Feix. 1992. Two different cDNAs encoding TFIID proteins of maize. FEBS Lett. 301: 294-298.

Hagemeier, C., S. Walker, R. Caswell, T. Kouzarides, and J. Sinclair. 1992. The human cytomegalovirus 80 -kilodalton but not the 72-kilodalton immediate early protein transactivates heterologous promoters in a TATA box-dependent mechanism and interacts directly with TFIID. I. Virol. 66: 44524456.

Hahn, S., S. Buratowski, P.A. Sharp, and L. Guarente. 1989. Isolation of the gene encoding the yeast TATA binding protein TFIID: A gene identical to the SPT15 suppressor of Ty elements insertions. Cell 58: 1173-1181.

Hernandez, N. 1992. Transcription of vertebrate snRNA genes and related genes. In Transcriptional regulation. Monograph 22 (ed. S. McKnight and K.R. Yamamoto), pp. 281-313. Cold Spring Harbor Laboratory Press, Cold Spring Harbor, New York.

Herschlag, D., and F.B. Johnson. 1993. Synergism in transcriptional activation: A kinetic view. Genes \& Dev. 7: 173-179.

Hisatake, K., S. Hasegawa, R. Takada, Y. Nakatani, M. Horikoshi, and R.G. Roeder. 1993. The p250 subunit of native TATA box-binding factor TFIID is the cell-cycle regulatory protein CCG1. Nature 362: 179-181.

Hoey, T., B.D. Dynlacht, M.G. Peterson, B.F. Pugh, and R. Tjian. 1990. Isolation and characterization of the Drosophila gene encoding the TATA box binding factor, TFIID. Cell 61: 1179-1186.

Hoey, T., R.O.J. Weinzierl, G. Gill, J.-L. Chen, B.D. Dynlacht, and R. Tjian. 1993. Molecular cloning and functional analysis of Drosophila TAFs reveal properties expected of coacti- vators. Cell 72: 247-260.

Hoffmann, A., M. Horikoshi, C.K. Wang, S. Schroeder, P.A. Weil, and R.G. Roeder. 1990a. Cloning of the Schizosaccharomyces pombe TFIID gene reveals a strong conservation of functional domains present in Saccharomyces cerevisiae TFIID. Genes \& Dev. 4: 1141-1148.

Hoffmann, A., E. Sinn, T. Yamamoto, J. Wang, A. Roy, M. Horikoshi, and R.G. Roeder. 1990b. Highly conserved core domain and unique $\mathrm{N}$ terminus with presumptive regulatory motifs in a human TATA factor (TFIID). Nature 346: 387390.

Holdsworth, M.J., C. Grierson, W. Schuch, and M. Bevan. 1992. DNA-binding properties of cloned TATA-binding protein from potato tubers. Plant Mol. Biol. 19: 455-464.

Horikoshi, M., C.K. Wang, H. Fujii, J.A. Cromlish, P.A. Weil, and R.G. Roeder. 1989a. Purification of a yeast TATA boxbinding protein that exhibits human transcription factor IID activity. Proc. Natl. Acad. Sci. 86: 4843-4847.

$-1989 \mathrm{~b}$. Cloning and structure of a yeast gene encoding a general transcription initiation factor TFIID that binds to the TATA box. Nature 341: 299-303.

Horikoshi, M., T. Yamamoto, Y. Ohkuma, P.A. Weil, and R.G. Roeder. 1990. Analysis of structure-function relationships of yeast TATA box binding factor TFID. Cell 61: 1171-1178.

Horikoshi, N., K. Maguire, A. Kralli, E. Maldonado, D. Reinberg, and R. Weinmann. 1991. Direct interaction between adenovirus E1A protein and the TATA box binding transcription factor IID. Proc. Natl. Acad. Sci. 88: 5124-5128.

Horikoshi, M., C. Bertuccioli, R. Takada, J. Wang, T. Yamamoto, and R. Roeder. 1992. Transcription factor TFIID induces DNA bending upon binding to the TATA element. Proc. Natl. Acad. Sci. 89: 1060-1064.

Huet, J. and A. Sentenac. 1992. The TATA-binding protein participates in TFIIIB assembly on tRNA genes. Nucleic Acids Res. 20: 6451-6454.

Ingles, C.J., M. Shales, W.D. Cress, S.J. Triezenberg, and J. Greenblatt. 1991. Reduced binding of TFIID to transcriptionally compromised mutants of VP16. Nature 351: 588-590.

Inostroza, J.A., F.H. Mermelstein, I. Ha, W.S. Lane, and D. Reinberg. 1992. Dr1, A TATA-binding protein-associated phosphoprotein and inhibitor of class II gene transcription. Cell 70: 477-489.

Jantzen, H.-M., A. Ming Chow, D.S. King, and R. Tjian. 1992. Multiple domains of the RNA polymerase I activator hUBF interact with the TATA-binding protein complex hSL1 to mediate transcription. Genes \& Dev. 6: 1950-1963.

Kao, C.C., P.M. Lieberman, M.C. Schmidt, Q. Zhou, R. Pei, and A.J. Berk. 1990. Cloning of a transcriptionally active human TATA binding factor. Science 248: 1646-1650.

Kassavetis, G.A., B.R. Braun, L.H. Nguyen, and E.P. Geiduschek. 1990. S. cerevisiae TFIIIB is the transcription initiation factor proper of RNA polymerase III, while TFIIIA and TFIIIC are assembly factors. Cell 60: 235-245.

Kassavetis, G.A., B. Bartholomew, J.A. Blanco, T.E. Johnson, and E.P. Geiduschek. 1991. Two essential components of the Saccharomyces cerevisiae transcription factor TFIIIB: Transcription and DNA-binding properties. Proc. Natl. Acad. Sci. 88: 7308-7312.

Kassavetis, G.A., C.A.P. Joazeiro, M. Pisano, E.P. Geiduschek, T. Colbert, S. Hahn, and J. A. Blanco. 1992. The role of the TATA-binding protein in the assembly and function of the multisubunit yeast RNA polymerase III transcription factor, TFIIIB. Cell 71: 1055-1064.

Kawata, T. M. Minami, T. Tamura, K. Sumita, and M. Iwabuchi. 1992. Isolation and characterization of a cDNA clone encoding the TATA box-binding protein (TFID) from wheat. Plant 
Mol. Biol. 19: 867-872

Kelleher, R.J. III, P.M. Flanagan, and R.D. Kornberg. 1990. A novel mediator between activator proteins and the RNA polymerase II transcription apparatus. Cell 61: 1209-1215.

Kelleher, R.J., P.M. Flanagan, D.I. Chasman, A.S. Ponticelli, K. Struhl, and R.D. Kornberg. 1992. Yeast and human TFIIDs are interchangeable for the response to acidic transcriptional activators in vitro. Genes \& Dev. 6: 296-303.

Klekamp, M.S. and P.A. Weil. 1986. Partial purification and characterization of the Saccharomyces cerevisiae transcription factor TFIIIB. J. Biol. Chem. 6: 2819-2827.

Kokubo, T., D.-W. Gong, S. Yamashita, M. Horikoshi, R.G. Roeder, and Y. Nakatani. 1993. Drosophila 230-kD TFIID subunit, a functional homolog of the human cell cycle gene product, negatively regulates DNA binding of the TATA box-binding subunit of TFIID. Genes \& Dev. 7: 1033-1046.

Koleske A.J., S. Buratowski, M. Nonet, and R.A. Young. 1992. A novel transcription factor reveals a functional link between the RNA polymerase II CTD and TFIID. Cell 69: 883-894.

Learned, R.M., S. Cordes, and R. Tjian. 1985. Purification and characterization of a transcription factor that confers promoter specificity to human RNA polymerase I. Mol. Cell. Biol. 5: 1358-1369.

Learned, R.M., T.K. Learned, M.M. Haltiner, and R.T. Tjian. 1986. Human rRNA transcription is modulated by the coordinate binding of two factors to an upstream control element. Cell 45: 847-857.

Lee, D.K., M. Horikoshi, and R.D. Roeder. 1991. Interaction of TFIID in the minor groove of the TATA element. Cell 67: 1241-1250.

Lee, W.S., C.C. Kao, G.O. Bryant, X. Liu, and A.J. Berk. 1991. Adenovirus E1A activation domain binds the basic repeat in the TATA box transcription factor. Cell 67: 365-376.

Lee, D.K., J. Dejong, S. Hashimoto, M. Horikoshi, and R. Roeder. 1992. TFIIA induces conformational changes in TFIID via interactions with the basic repeat. Mol. Cell. Biol. 12: 5189-5196.

Lieberman, P.M. and A.J. Berk. 1991. The Zta trans-activator protein stabilizes TFIID association with promoter DNA by direct protein-protein interaction. Genes \& Dev. 5: 24412454.

Lin, Y.-S. and M.R. Green. 1991. Mechanism of action of an acidic transcriptional activator in vitro. Cell 64: 971-981.

Lin, Y.-S., M. Carey, M. Ptashne, and M.R. Green. 1990. How different encaryotic transcriptional activators can cooperate promiscuously. Nature 345: 359-361.

Lobo, S.M. and N. Hernandez. 1989. A 7 bp mutation converts a human RNA polymerase II snRNA promoter into an RNA polymerase III promoter. Cell 58: 55-67.

Lobo, S.M., J. Lister, M.L. Sullivan, and N. Hernandez. 1991. The cloned RNA polymerase II transcription factor IID selects RNA polymerase III to transcribe the human U6 gene in vitro. Genes \& Dev. 5: 1477-1489.

Lobo, S.M., M. Tanaka, M.L. Sullivan, and N. Hernandez. 1992. A TBP complex essential for transcription from TATA-less but not TATA-containing RNA polymerase III promoters is part of the TFIIIB fraction. Cell 71: 1029-1040.

Lopez-de-Leon, A., M. Librizzi, K. Tuglia, and I. Willis. 1992. PCF4 encodes an RNA polymerase III transcription factor with homology to TFIIIB. Cell 71: 211-220.

Maldonado, E., I. Ha, P. Cortes, L. Weis, and D. Reinberg. 1990. Factors involved in specific transcription by mammalian RNA polymerase II: Role of transcription factors IIA, IID, and IIB during formation of transcription-competent complex. Mol. Cell. Biol. 10: 6335-6347.

Margottin, F., G. Dujardin, M. Gerard, J.-M. Egly, J. Huet, and A.
Sentenac. 1991. Participation of the TATA factor in transcription of the yeast U6 gene by RNA polymerase C. Science 251: 424-426.

Matsui, T., J. Segall, P.A. Weil, and R.G. Roeder. 1980. Multiple factors required for accurate initiation of transcription by purified RNA polymerase II. I. Biol. Chem. 255: 1199211996.

Mattaj, I.W., N.A. Dathan, H.W. Parry, P. Carbon, and A. Krol. 1988. Changing the RNA polymerase specificity of U snRNA gene promoters. Cell 55: 435-442.

McAndrew, M.B., M. Read, P.F.G. Sims, and J.E. Hyde. 1993. Characterisation of the gene encoding an unusually divergent TATA-binding protein (TBP) from the extremely A $+\mathrm{T}$ rich human malaria parasite Plasmodium falciparum. Gene 124: 165-171.

Meissner, W., R. Holland, R. Waldschmidt, and K.H. Seifart. 1993. Transcription factor IIA stimulates the expression of classical polIII genes. Nucleic Acids Res. 21: 1013-1018.

Meisterernst, M. and R.G. Roeder. 1991. Family of proteins that interact with TFIID and regulate promoter activity. Cell 67: 557-567.

Meisterernst, M., A.L. Roy, H. Mei Lieu, and R.G. Roeder. 1991. Activation of class II gene transcription by regulatory factors is potentiated by a novel activity. Cell 66: 981-993.

Muhich, M.L., C.T. Lida, M. Horikoshi, R.G. Roeder, and C.S. Parker. 1990. cDNA clone encoding Drosophila transcription factor TFIID. Proc. Natl. Acad. Sci. 87: 9148-9152.

Nakajima, N., M. Horikoshi, and R.G. Roeder. 1988. Factors involved in specific transcription by mammalian RNA polymerase II: Purification, genetic specificity, and TATA boxpromoter interactions of TFIID. Mol. Cell. Biol. 8: 40284040.

Nikolov, D.B., S.-H. Hu, J. Lin, A. Gasch, A. Hoffmann, M. Horikoshi, N.-H. Chua, R.G. Roeder, and S.K. Burley. 1992. Crystal structure of TFIID TATA-box binding protein. $\mathrm{Na}$ ture 360: $40-46$.

O'Shea-Greenfield, A. and S.T. Smale. 1992. Roles of TATA and initiator elements in determining the start site location and direction of RNA polymerase II transcription. I. Biol. Chem. 267: 1391-1402.

Peterson, M.G., N. Tanese, B.F. Pugh, and R. Tjian. 1990. Functional domains and upstream activation properties of cloned human TATA binding protein. Science 248: 1625-1630.

Poon, D., R.A. Knittle, K.A. Sabelko, T. Yamamoto, M. Horikoshi, R.G. Roeder, and P.A. Weil. 1993. Genetic and biochemical analyses of yeast TATA-binding protein mutants. J. Biol. Chem. 268: 5005-5013.

Pugh, B.F. and R. Tjian. 1990. Mechanism of transcriptional activation by $\mathrm{Spl}$ : Evidence for coactivators. Cell 61: 11871197.

- 1991. Transcription from a TATA-less promoter requires a multisubunit TFIID complex. Genes \& Dev. 5: 1935-1945.

Reddy, P. and S. Hahn. 1991. Dominant negative mutations in yeast TFIID define a bipartite DNA-binding region. Cell 65: 349-357.

Reeder, R.H. 1992. Regulation of transcription by RNA polymerase I. In Transcriptional regulation. Monograph 22 led. S. McKnight and K.R. Yamamoto), pp. 315-348. Cold Spring Harbor Laboratory Press, Cold Spring Harbor, New York.

Roeder, R.G. 1991. The complexities of eucaryotic transcription initiation: Regulation of preinitiation complex. Trends Biochem. Sci. 16: 402-408.

Roy, A.L., M. Meisterernst, P. Pognonec, and R.G. Roeder. 1991. Cooperative interaction of an initiator-binding transcription initiation factor and the helix-loop-helix activator USF. $\mathrm{Na}$ - 
ture 354: 245-248.

Ruppert, S., E.H. Wang, and R. Tjian. 1993. Cloning and expression of human $\mathrm{TAF}_{\mathrm{H}}$ 250: A TBP-associated factor implicated in cell-cycle regulation. Nature 362: 175-179.

Sadowski, C.L., R.W. Henry, S.M. Lobo, and N. Hernandez. 1993. Targeting TBP to a non-TATA box cis-regulatory element: A TBP-containing complex activates RNA polymerase II and III transcription from snRNA promoters through the PSE. Genes \& Dev. (in press).

Samuels, M., A. Fire, and P.A. Sharp. 1982. Separation and characterization of factors mediating accurate transcription by RNA polymerase II. $J$. Biol. Chem. 257: 14419-14427.

Sawadogo, M. and A. Sentenac. 1990 . RNA polymerase B (II) and general transcription factors. Annu. Rev. Biochem. 59: 711754.

Schmidt, M.C., C.C. Kao, R. Pei, and A.J. Berk. 1989. Yeast TATA box transcription factor gene. Proc. Natl. Acad. Sci. 86: 7785-7789.

Schultz, M.C., R.H. Reeder, and S. Hahn. 1992. Variants of the TATA-binding protein can distinguish subsets of RNA polymerase I, II, and III promoters. Cell 69: 697-702.

Segall, J., T. Matsui, and R.G. Roeder. 1980. Multiple factors are required for the accurate transcription of purified genes by RNA polymerase III. J. Biol. Chem. 255: 11986-11991.

Sekiguchi, T., T. Miyata, and T. Nishimoto. 1988. Molecular cloning of the cDNA of human chromosomal gene (CCG1) which complements the temperature-sensitive G1 mutants, tsBN462 and ts 13 , of the BHK cell line. EMBO J. 7: 16831687.

Sekiguchi, T., Y. Nohiro, Y. Nakamura, N. Hisamoto, and T. Nishimoto. 1991. The human CCG1 gene essential for progression of the $G_{1}$ phase, encodes a 210-kilodalton nuclear DNA-binding protein. Mol. Cell. Biol. 11: 3317-3325.

Seto, E., Y. Shi, and T. Shenk. 1991. YY1 is an initiator sequence-binding protein that directs and activates transcription in vitro. Nature 354: 241-245.

Seto, E., A. Usheva, G.P. Zambetti, J. Momand, N. Horikoshi, R. Weinmann, A. J. Levine, and T. Shenk. 1992. Wilt-type p53 binds to the TATA-binding protein and represses transcription. Proc. Natl. Acad. Sci. 89: 12028-12032.

Shi,Y., E. Seto, L.-S. Chang, and T. Shenk. 1991. Transcriptional repression by YYl, a human GLl-Kruppel-related protein, and relief of repression by adenovirus E1A protein. Cell 67: $377-388$.

Simmen, K.A., J. Bernues, H.D. Parry, H.G. Stunnenberg, A. Berkenstam, B. Cavallini, J.-M. Egly, and I.W. Mattaj. 1991. TFIID is required for in vitro transcription of the human U6 gene by RNA polymerase III. EMBO /. 10: 1853-1862.

Simmen, K.A., J. Bernues, J.D. Lewis, and I.W. Mattaj. 1992. Cofractionation of the TATA-binding protein with the RNA polymerase III transcription factor TFIIIB. Nucleic Acids Res. 20: $5889-5898$.

Smale, S.T. and D. Baltimore. 1989. The "initiator" as a tran scriptional element. Cell 57: 103-113.

Smale, S.T., M.C. Schmidt, A.J. Berk, and D. Baltimore. 1990. Transcriptional activation by $\mathrm{Spl}$ as directed through TATA or initiator: Specific requirements for mammalian transcription factor IID. Proc. Natl. Acad. Sci. 87: 4509-4513.

Starr, D.B. and D.K. Hawley. 1991. TFIID binds in the minor groove of the TATA box. Cell 67: 1231-1240.

Stringer, K.F., C.J. Ingles, and J. Greenblatt. 1990. Direct and selective binding of an acidic transcriptional activation domain to the TATA-box factor TFIID. Nature 345: 783-786.

Strubin, M. and K. Struhl. 1992. Yeast and human TFIID with altered DNA-binding specificity for TATA elements. Cell 68: $721-730$
Sumimoto, H., Y. Ohkuma, T. Yamamoto, M. Horikoshi, and R.G. Roeder. 1990. Factors involved in specific transcription by mammalian RNA polymerase II: Identification of general transcription factor TFIIG. Proc. Natl. Acad. Sci. 87: 91589162.

Taggart, A.K.P., T.S. Fisher, and B.F. Pugh. 1992. The TATAbinding protein and associated factors are components of pol III transcription factor TFIIIB. Cell 71: 1015-1028.

Takada, R., Y. Nakatani, A. Hoffmann, T. Kokubo, S. Hasegawa, R.G. Roeder, and M. Horikoshi. 1992. Identification of human TFIID components and direct interaction between a 250-kD polypeptide and the TATA box-binding protein (TFIID ${ }_{\tau}$ ). Proc. Natl. Acad. Sci. 89: 11809-11813.

Tamura, T., K. Sumita, I. Fujino, A. Aoyama, M. Horikoshi, A. Hoffmann, R.G. Roeder, M. Muramatsu, and K. Mikoshiba. 1991. Striking homology of the "variable" $\mathrm{N}$-terminal as well as the "conserved core" domains of the mouse and human TATA-factors (TFIID). Nucleic Acids. Res. 19: 38613865.

Tanese, N., B.F. Pugh, and R. Tjian. 1991. Coactivators for a proline-rich activator purified from the multisubunit human TFIID complex. Genes \& Dev. 5: 2212-2224.

Timmers, H.Th.M. and P.A. Sharp. 1991. The mammalian TFIID protein is present in two functionally distinct complexes. Genes \& Dev. 5: 1946-1956.

Timmers, H.Th.M, R.E. Meyers, and P.A. Sharp. 1992. Composition of transcription factor B-TFIID. Proc. Natl. Acad. Sci. 89: 8140-8144.

Truant, R., H. Xiao, C.J. Ingles, and J. Greenblatt. 1993. Direct interaction between the transcriptional activation domain of human p53 and the TATA box-binding protein. J. Biol. Chem. 268: 2284-2287.

Usheva, A., E. Maldonado, A. Goldring, H. Lu, C. Houbavi, D. Reinberg, and Y. Aloni. 1992. Specific interactions between the nonphosphorylated form of RNA polymerase II and the TATA-binding protein. Cell 69: 871-881.

Van Dyke, M.W., R.G. Roeder, and M. Sawadogo. 1988. Physical analysis of transcription preinitiation complex assembly on a class II gene promoter. Science 241: 1335-1338.

Van Dyke, M.W., M. Sawadogo, and R.G. Roeder. 1989. Stability of transcription complexes on class II genes. Mol. Cell. Biol. 9: 342-344.

Waldschmidt, R., D. Jahn, and K.H. Seifart. 1988. Purification of transcription factor IIIB from HeLa cells. I. Biol. Chem. 263: $13350-13356$

Waldschmidt, R., I. Wanandi, and K.H. Seifart. 1991. Identification of transcription factors required for the expression of mammalian U6 genes in vitro. EMBO J. 10: 2595-2603.

Weinzierl, R.O.J., B.D. Dynlacht, and R. Tjian. 1993. Largest subunit of Drosophila transcription factor IID directs assembly of a complex containing TBP and a coactivator. Nature 362: $511-517$.

Weis, L. and D. Reinberg. 1992. Transcription by RNA polymerase II: Initiator-directed formation of transcription-competent complexes. FASEB J. 6: 3300-3309.

White, J.H., C. Brou, J. Wu, N. Burton, J.-M. Egly, and P. Chambon. 1991. Evidence for a factor required for transcriptional stimulation by the chimeric acidic activator GAL-VP16 in HeLa cell extracts. Proc. Natl. Acad. Sci. 88: 7674-7678.

White, J.H., C. Brou, J. Wu, Y. Lutz, V. Moncollin, and P. Chambon. 1992. The acidic transcriptional activator GAL-VP16 acts on preformed template-committed complexes. EMBO I. 11: 2229-2240.

White, R.J. and S.P. Jackson. 1992. Mechanism of TATA-binding protein recruitment to a TATA-less class III promoter. Cell 71: 1041-1053. 
White, R.J., S.P. Jackson, and P.W.J. Rigby. 1992. A role for the TATA-box-binding protein component of the transcription factor IID complex as a general RNA polymerase III transcription factor. Proc. Natl. Acad. Sci. 89: 1949-1953.

Wiley, S.R., R.J. Kraus, and J.E. Mertz. 1992. Functional binding of the "TATA" box binding component of transcription factor TFIID to the -30 region of TATA-less promoters. Proc. Natl. Acad. Sci. 89: 5814-5818.

Wong, J.-M., F. Liu, and E. Bateman. 1992. Cloning and expression of the Acanthamoeba castellanii gene encoding transcription factor TFIID. Gene 117: 91-97.

Yamamoto, T., M. Horikoshi, J. Wang, S. Hasegawa, P.A. Weil, and R.G. Roeder. 1992. A bipartite DNA binding domain composed of direct repeats in the TATA box binding factor TFIID. Proc. Natl. Acad. Sci. 89: 2844-2848.

Zawel, L. and D. Reinberg. 1992. Advances in RNA polymerase II transcription. Curr. Opin. Cell Biol. 4: 488-495.

. 1993. Initiation of transcription by RNA polymerase II: A mulit-step process. Prog. Nucleic Acids Res. Mol. Biol. 44: 67-108.

Zhou, Q., M.C. Schmidt, and A.J. Berk. 1991. Requirement for acidic amino acid residues immediately $\mathrm{N}$-terminal to the conserved domain of Saccharomyces cerevisiae TFIID. EMBO I. 10: 1843-1852.

Zhou, Q., P.M. Lieberman, T.G. Boyer, and A.J. Berk. 1992. Holo-TFIID supports transcriptional stimulation by diverse activators and from a TATA-less promoter. Genes \& Dev. 6: 1964-1974.

Zhou, Q., T.G. Boyer, and A.J. Berk. 1993. Factors (TAFs) required for activated transcription interact with TATA-box binding protein conserved core domain. Genes \& Dev. 7: 180-187.

Zhu, H. and R. Prywes. 1992. Identification of a coactivator that increases activation of transcription by serum response factor and GAL4-VP16 in vitro. Proc. Natl. Acad. Sci. 89: 52915295. 


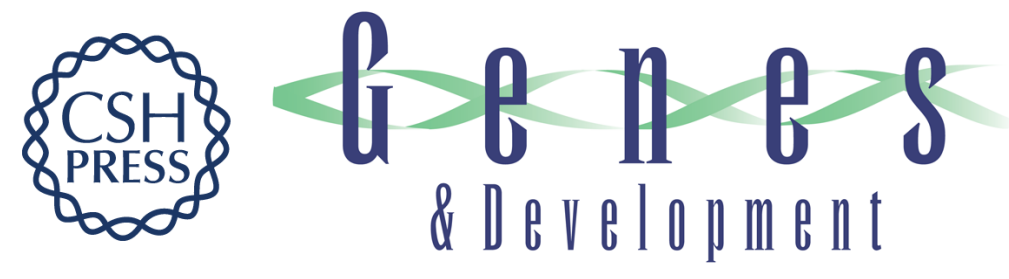

\section{TBP, a universal eukaryotic transcription factor?}

N Hernandez

Genes Dev. 1993, 7:

Access the most recent version at doi:10.1101/gad.7.7b.1291 $\begin{array}{ll}\text { References } & \begin{array}{l}\text { This article cites } 146 \text { articles, } 60 \text { of which can be accessed free at: } \\ \text { http://genesdev.cshlp.org/content/7/7b/1291.full.html\#ref-list-1 }\end{array}\end{array}$

\section{License}

Email Alerting

Receive free email alerts when new articles cite this article - sign up in the box at the Service top right corner of the article or click here.

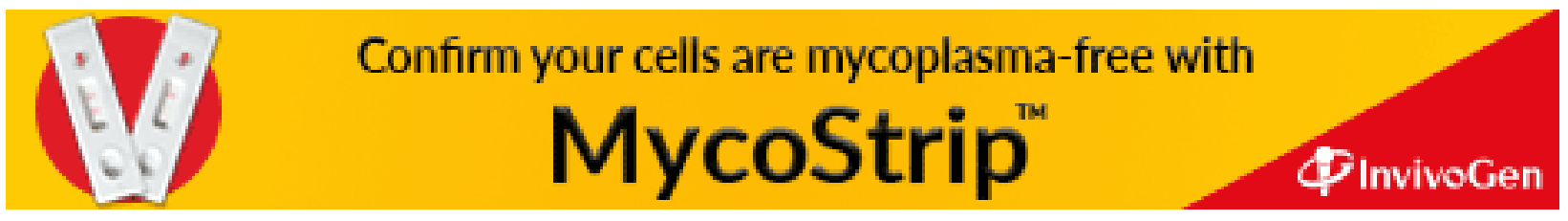

